\title{
PROCESS AND ANALYTICAL STUDIES OF ENHANCED LOW SEVERITY CO-PROCESSING USING SELECTIVE COAL PRETREATMENT
}

$\mathrm{DOE} / \mathrm{PC} / 88812--\mathrm{T} 13$

DE92 007898

\section{Chemical Engineering and Petroleum Refining Dept. colorado school of Mines Golden, Co 80401}

\section{DISCLAIMER}

This report was prepared as an account of work sponsored by an agency of the United States Government. Neither the United States Government nor any agency thereof, nor any of their employees, makes any warranty, express or implied, or assumes any legal liability or responsibility for the accuracy, completeness, or usefulness of any information, apparatus, product, or process disclosed, or represents that its use would not infringe privately owned rights. Reference herein to any specific commercial product, process, or service by trade name, trademark, manufacturer, or otherwise does not necessarily constitute or imply its endorsement, recommendation, or favoring by the United States Government or any agency thereof. The views and opinions of authors expressed herein do not necessarily state or reflect those of the United States Government or any agency thereof. Quarterly Technical Progress Report for the Period
March - May, 1990

DOE Contract NO. DE-AC22-88PC88812 


\section{ABSTRACT}

This report describes progress on research during the sixth quarter of this contract dealing with applications of coal pretreatment techniques in coal hydroliquefaction. The objectives of the project are to investigate various coal pretreatment techniques and to determine the effect of these pretreatment procedures on the reactivity of the coal. Reactivity enhancement will be evaluated under both direct hydroliquefaction and co-processing conditions. coal conversion utilizing low rank coals and low severity conditions (reaction temperatures generally less than 350 ${ }^{\circ}$ ) ) are the primary focus of the liquefaction experiments, as it is expected that the effect of pretreatment conditions and the attendant reactivity enhancement will be greatest for these coals and at these conditions.

This document presents a comprehensive report summarizing the findings on the effect of mild alkylation pretreatment on coal reactivity under both direct hydroliquefaction and liquefaction co-processing conditions. Results of experiments using a dispersed catalyst system (chlorine) are also presented for purposes of comparison. In general, mild alkylation has been found to be an effective pretreatment method for altering the reactivity of coal. Selective (oxygen) methylation was found to be more effective for high oxygen (subbituminous) coals compared to coals of higher rank. This reactivity enhancement was evidenced under both low and high severity liquefaction 
conditions, and for both direct hydroliquefaction and liquefaction co-processing reaction environments. Nonselective alkylation (methylation) was also effective, although the enhancement was less pronounced than than found for coals activated by o-alkylation. The degree of reactivity enhancement was found to vary with both Iiquefaction and/or co-processing conditions and coal type, with the greatest positive effect found for subbituminous coal which had been selectively o-methylated and subsequently liquefied at low severity reaction conditions. 
TABLE OF CONTENTS

$\underline{\text { PAGE }}$

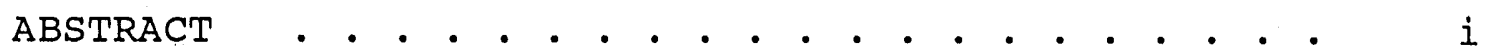

TABLE OF CONTENTS . . . . . . . . . . . . . . . . . iii

INTRODUCTION . • • . . . . . . . . . . . . . . . 1

1. Introduction . . . . . . . . . . . 1

2. Project objective . . . . . . . 2

EXPERIMENTAL PROCEDURE . . . . . . . . . . . . . . 4

1. Experimental Design . . . . . . . 4

2. Materials . . . . . . . . . 7

2.1 Coals . . . . . . . . . 7

2.2 Solvents . . . . . . . . 7

2.3 Reaction Gas ......... . 9

3. Coal Pretreatment Methods . . . . 9

3.1 Determination of Extent of

Alkylation . . . . . . . . . 11

3.2 Reductive Alkylation . . . . . 14

3.3 Oxygen Alkylation . . . . . 16

3.4 Chlorine Catalyst/Mild Alkylation Pretreatment . . . . . . . 17

4. Coal Liquefaction Measurements. . . 18

4.1 Equipment Description . . . . 18

4.2 Experimental Procedure . . . . 23

4.3 Liquefaction Product Recovery . 26 
5. Moisture Fraction Determination . . $\quad 27$

6. Ash Fraction Determination . . . . 28

DISCUSSION OF RESULTS . . . . . . . . . . . . . 31

1. Coal Pretreatment . . . . . . . 31

1.1 oxygen Alkylation . . . . . 33

1.2 Reductive Alkylation . . . . 33

1.3 Chlorine Catalyst/Mild Alkylation Pretreatment... . . . . . 34

1.3.1 Extent of Alkylation . . 34

1.3.2 Extent of Dispersed

Chlorine Incorporation. . 34

2. Intrinsic THF Solubility of Coal. . . 35

3. Calculation of Coal Conversion. . . 37

4. Reactivity Parameter Matrix . . . . 38

5. Liquefaction Reactivity Experiments . 41

5.1 Oxygen Alkylation Pretreatment . 44

5.2 Reductive Alkylation Pretreatment 48

5.3 Chlorine Catalyst/Mild Alkylation Pretreatment......... 52

6. Co-Processing Reactivity Experiments. $\quad 55$

6.1 Oxygen Alkylation Pretreatment • 58

6.2 Reductive Alkylation Pretreatment 62

6.3 Chlorine Catalyst/Mild Alkylation
Pretreatment......... 65

7. Optimization of Liquefaction Conditions 68 CONCLUSIONS. . . . . . . . . . . . . . . . . 73 
RECOMMENDATIONS. •. . . . . . . . . . . . . 76

REFERENCES CITED • • . . . . . . . . . . . . 77

APPENDICES • . . . . . . . . . . . . . . 78

A: Liquefaction/Co-Processing Data . . 78

B: Analysis of Variance. . . . . . . 91 
INTRODUCTION

If coal liquefaction is ever to become an economical source of liquid fuels, liquefaction processes must be developed which can compete with energy sources presently in use. Development of low severity (temperature, pressure and reaction time) liquefaction processes is one such alternative that has recently received increased emphasis. Liquefaction processes which operate at lower temperatures and pressures (temperatures below $350{ }^{\circ} \mathrm{C}$ and pressures below 10 $\mathrm{MPa}$ ) require lower capital costs while maintaining a high degree of selectivity to liquid products. The production of undesired hydrocarbon gases is minimized, resulting in reduced hydrogen consumption and improved economics over high severity liquefaction processes." The main disadvantage of using lower severity liquefaction processes is the increased reaction (residence) time required due to the fact that at lower severity the rate of coal dissolution is slower. Maximization of coal conversion is normally not the primary concern when low severity liquefaction is employed as the first stage of a two stage liquefaction process. In two stage processes, the first stage is geared towards obtaining a satisfactory dissolution rate and a liquid product distribution where asphaltenes are preferred over the less reactive preasphaltenes. This results in an intermedi- 
ate coal-derived product stream which is less refractory and more amenable to subsequent upgrading in a higher severity catalytic second stage.

The disadvantages of low severity liquefaction in terms of coal reactivity could be offset by pretreatment of the coal prior to first stage processing. This would result in improved operating characteristics for the first stage process while still maintaining a product composition which is suitable for subsequent upgrading in the second stage process. The objective of this research program was to investigate a variety of coal pretreatment methods, and determine the effect of these processes on the reactivity of coal. Coal reactivity measurements were made at both low and high severity conditions, and in both liquefaction and coprocessing reaction environments. This report presents the results of experiments performed to investigate use of mild alkylation and addition of a dispersed catalyst as coal pretreatment steps. Different liquefaction conditions were used in order to determine which pretreatment methods would be most suitabie as precursors to first stage, low severity liquefaction processes. Both bituminous and subbituminous coal samples were chosen in order to observe how the effectiveness of different pretreatment methods varied with coal rank. Two different liquefaction solvents were used, 
resulting in two separate sets of reactivity data. The first solvent was dihydrophenanthrene (DHP), which was chosen in order to determine the effect of coal pretreatment on reactivity under direct hydrogenation conditions. The second solvent utilized was cold Lake atmospheric residuum, in order to simulate operation and measure coal reactivity under coal/oil co-processing conditions. The pretreated samples were liquefied at different combinations of these reaction variables, resulting in two sets of liquefaction data for different ranks of coal, reaction times, and temperatures. Coal reactivities were compared in terms of the extent to which the coal was converted to THF soluble material during liquefaction, and comparisons were made between the pretreated and the untreated coals at each set of liquefaction conditions. 
EXPERIMENTAL PROCEDURE

\section{EXPERIMENTAL DESIGN}

The objective of this program is to investigate the manner in which selected pretreatment methods affect the reactivity enhancement of differently ranked coals. Reactivity enhancement" was measured by Iiquefaction of the pretreated coal at both low and high severity reaction conditions using both co-processing and direct liquefaction solvents. As shown in Table $I$, each combination of reaction severity and mode of processing (direct liquefaction or co-processing) was run at short and longer reaction times to observe how the enhancement by pretreatment varied with reaction time.

Two coals, Illinois \#6 bituminous and wyodak subbituminous, were selected so that pretreatment effects could be compared as a function of coal rank. A matrix of reactivity experiments, shown in Table II, was rompleted to evaluate the effect of each variable listed in Table I. Both pretreated and untreated coals were used in completing the matrix so that the effect of the pretreatment method at each combination of liquefaction conditions could be direct1y determined. 
TABLE II

Matrix of Liquefaction Reaction Parameters

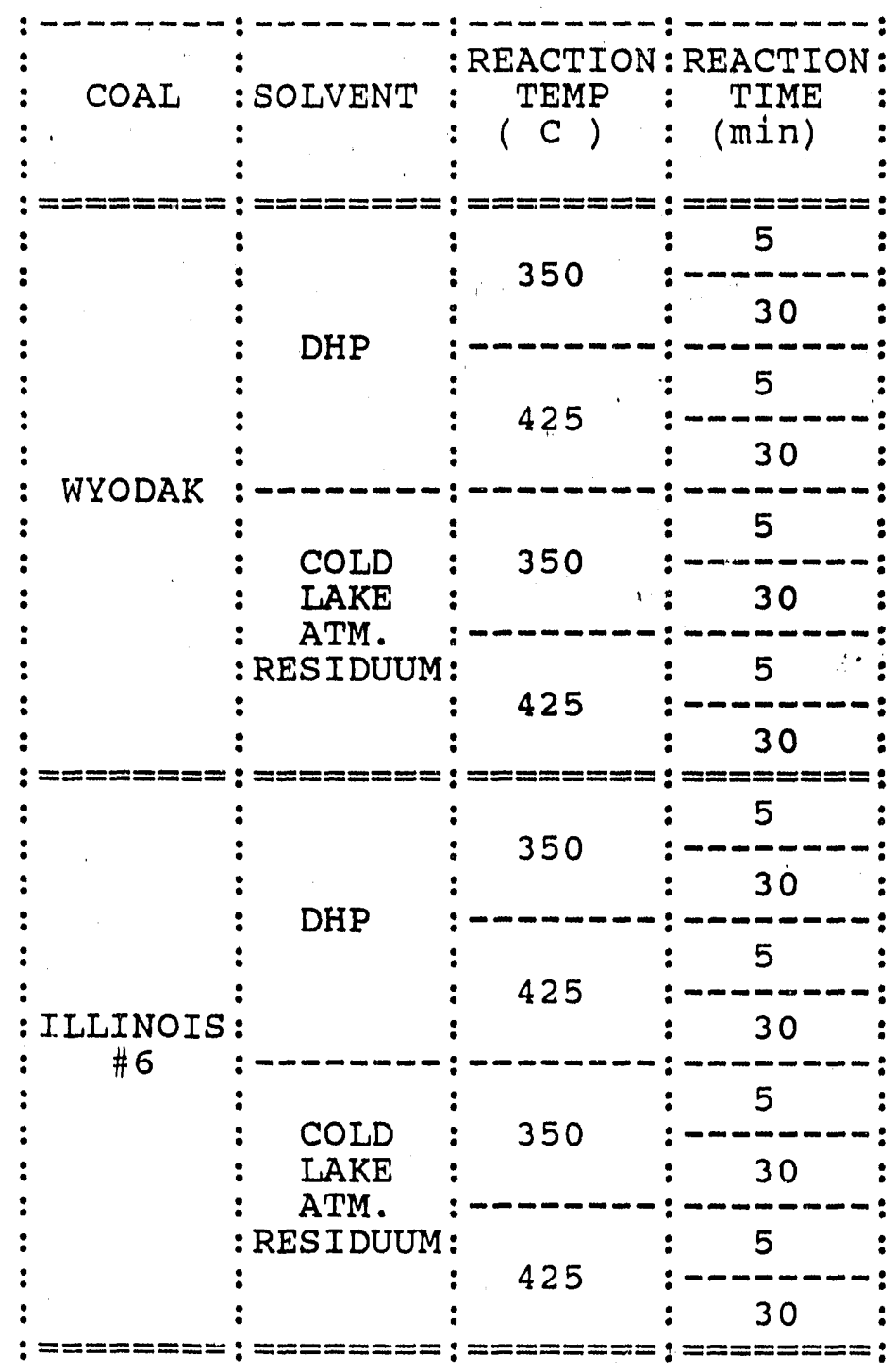




\section{MATERIALS}

\section{$\underline{2.1 \mathrm{Coals}}$}

The experimental design used involved using Illinois \#6 bituminous and Wyodak subbituminous coals. An analysis of the coal properties is shown in Table III. All coal samples used in the pretreatment experiments and subsequent Iiquefaction experiments were obtained from the Argonne Premium Coal Bank in $5 \mathrm{~g}$ ampoules of -100 mesh coal. Each ampoule was nitrogen purged to prevent oxidation of the sample prior to use. Ampoules were kept intact until the instant they were needed; any coal left beyond the amount required for each pretreatment process was discarded. This procedure assured that the coals used in all experimental work were essentially free of oxidation.

\subsection{Solvents}

Two different solvents were used in the liquefaction reactivity experiments. Dihydrophenanthrene (DHP) was chosen as the liquefaction solvent based upon its excellent hydrogen donor capabilities. The DHP sample used was obtained from the Aldrich Chemical co., with a purity of $94.0 \%$ by weight. Cold Lake atmospheric petroleum residuum was used to simulate coal reactivity liquefaction performance under co-processing conditions. Cold Lake residuum 
TABLE III

Feed Coal Properties

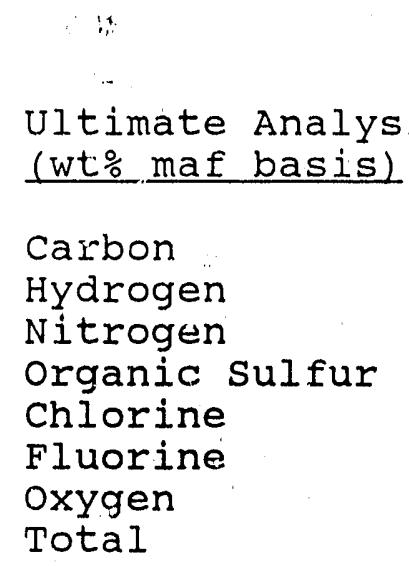

Illinois \#6

Bituminous

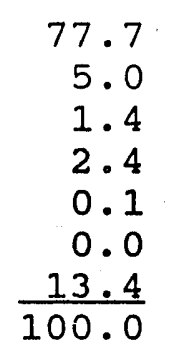

Wyodak

Subbituminous

$$
\begin{array}{r}
75.0 \\
5.4 \\
1.1 \\
0.5 \\
0.0 \\
0.0 \\
18.0 \\
\hline 100.0
\end{array}
$$


is a low grade petroleum solvent, containing about 85 wt: $455{ }^{\circ} \mathrm{C}$ material as shown in Table IV. In order to facilitate its use in the coal liquefaction experiments, $100 \mathrm{~g}$ samples of cold Lake residuum were hydrotreated using an Autoclave Magnedrive II $300 \mathrm{~cm}^{3}$ batch reactor. Hydrotreating involved the addition of $10.0 \mathrm{~g}$ of Shell $324 \mathrm{Ni} / \mathrm{Mo}$ Catalyst which was sulfided in-situ by the addition of $2.00 \mathrm{~g}$ of methyl sulfide. The reactor was then charged with $15.5 \mathrm{MPa}$ hydrogen gas, and heated to $400{ }^{\circ} \mathrm{C}$ for $1 \mathrm{hr}$. After hydrotreating, the catalyst was separated via centrifugation, resulting in a less viscous and more manageable coprocessing soivent. The hydrotreated cold Lake residuum was distilled using a micro-spinning band distillation column; distillation data are listed in Table IV.

\subsection{Reaction Gas}

The reaction gas used for the coal liquefaction experiment was hydrogen, which was obtained in industrial grade from General Air Services, Inc.

\section{COAL PRETREATMENT METHODS}

For each of the pretreatment methods used, the quantity of coal pretreated and scheduling of the pretreatment process were chosen to minimize coal waste and aging prior to 
TABLE IV

Properties of Cold Lake Atmospheric Residuum

Distillate Yields

$$
\begin{aligned}
& \text { Distillate } \\
& \text { Boiling } \\
& \text { Range. }
\end{aligned}
$$

Water

IBP - $177^{\circ} \mathrm{C}$

$177-455{ }^{\circ} \mathrm{C}$

$455+$

Total

${ }^{\circ} \mathrm{C}$

Ultimate Analysis

\section{Component}

Carbon

Hydrogen

Nitrogen

oxygen

Sulfur

Ash

Total
WEIGHT PERCENT DISTILLED

As Received After Hydrotreatment

$$
\begin{array}{r}
0.0 \\
0.0 \\
25.1 \\
74.9 \\
\hline 100.0
\end{array}
$$$$
0.0
$$$$
0.0
$$$$
32.0
$$$$
\frac{68.0}{100.0}
$$

WEIGHT PERCENT

As Received After Hydrotreatment

$$
\begin{array}{r}
88.3 \\
8.1 \\
1.0 \\
1.7 \\
0.9 \\
0.0 \\
\hline 100.0
\end{array}
$$

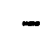

$-$

$-$

$-$

$-$

$-$ 
the liquefaction experiments. Pretreated coals were analyzed using Fourier transform infra-red spectroscopy (FTIR) and elemental analysis. Each pretreatment procedure and FTIR analysis of the pretreated coal was performed by Ms. Onranong Nguanprasert. Elemental analysis of each pretreated sample was performed by Huffman Laboratories, of Golden, Colorado.

Prior to liquefaction studies using pretreated coals, each method was repeated a number of times and the subsequent coal samples analyzed. Once the pretreatment process was deemed reproducible, a fresh batch of coal was pretreated, samples were withdrawn for analysis and the balance of the pretreated coal was stored under vacuum for use in liquefaction reactivity experiments.

\subsection{Determination of Extent of Alkylation}

The extent of alkylation for each pretreatment method was determined by elemental analysis of the alkylated coal in order to determine the hydrogen to carbon ratio. Hydrogen to carbon ratios of the untreated coals were determined using information supplied by the Argonne National Laboratory (1). The extent of alkylation due to the pretreatment method was calculated using the following equation: 


$$
x=100 *(C 3-C 1) /(C 2-C 3)
$$

where:

$\mathrm{X}$ is the extent of alkylation (grams of alkyl groups added per 100 grams of parent MAF coal),

$\mathrm{Cl}$ is the normalized weight fraction of carbon in the untreated feed coal $\{(w t \div C) /(w t \div C+w t \div H)\}$,

C2 is the normalized weight fraction of carbon in the alkyl group being introduced into the coal,

C3 is the normalized weight fraction of carbon in the alkylated coal.

The extent of alkylation can also be defined in terms of the number of alkyl groups added per 100 carbon atoms of moisture and ash free (WAF) coal:

$$
A=(X * M W C) /(\text { MWA * MFC })
$$

where:

A is the extent of alkylation in terms of number of alkyl groups added per 100 carbon atoms of MAF coal,

$\mathrm{x}$ is the extent of alkylation (grams of alkyl groups added per 100 grams of MAF coal),

MWC is the molecular weight of carbon (12.01),

MWA is the molecular weight of the alkyl group being incorporated into the coal,

MFC is the mass fraction of carbon in the untreated coal on a MAF basis. 
An example of how these equations are used is shown below, given the elemental analysis data for the raw and alkylated coal in the following table:

\begin{tabular}{lrrr}
\multicolumn{4}{c}{ MAF BASIS } \\
$\begin{array}{c}\text { WT \% } \\
\text { CAMPLE }\end{array}$ & $\begin{array}{r}\text { WT } \% \\
\text { CARON }\end{array}$ & HYDROGEN & \multicolumn{1}{c}{ RATIO } \\
RAW WYODAK & 75.01 & 5.35 & $0.9334<\mathrm{C} 1$ \\
METHYL GROUP & 12.01 & 3.03 & $0.7985<\mathrm{C} 2$ \\
TREATED WYODAK & 72.33 & 5.36 & $0.9310<\mathrm{C3}$ \\
& $\mathrm{X}=$ & $\mathrm{A}=$ & 1.94
\end{tabular}

The untreated Wyodak coal has a composition of 75.01 weight percent carbon and 5.35 weight percent hydrogen, as seen in the first row. The thira column uses these two values to calculate the normalized weight percent carbon (C1). For methyl group addition, the normalized weight percent carbon for a methyl (-CH3) group is shown in the second row (C2). Using the carbon and hydrogen analysis results from the treated coal sample, $C 3$ is calculated in the third row. These values are then used to calculate the extent of alkylation ( $\mathrm{X}$ ), with the resulting value of 1.82 grams of alkyl groups per 100 grams of MAF coal.

The extent of alkylation in terms of alkyl groups added per 100 carbon atoms (A), can be calculated using 75.01 weight percent carbon as the value for MFC in the untreated 
coal, 12.01 for the value of MWC, and 15.04 for the value of MWA. The resulting value for $A$ is 1.94 methyl groups added per 100 carbon atoms.

\subsection{Reductive Alkylation}

Coal pretreatment by reductive alkylation was based upon the work of Sternberg (2). The recipe used was based upon approximately $5 \mathrm{~g}$ of raw coal. If 2 ampoules of feed coal were required $(10 \mathrm{~g})$, then all of the accompanying reagents required to alkylate a $5 \mathrm{~g}$ batch of coal were doubled. The most coal alkylated at any one time was 4 ampoules (about 20 g) in a single alkylation experiment. For each $5 \mathrm{~g}$ of coal to be alkylated, $120 \mathrm{ml}$ of tetrahydrofuran (THF) were added to a round-bottomed, three necked flask. Approximately 4.4 $\mathrm{g}$ of potassium metal and $0.304 \mathrm{~g}$ of naphthalene were added to the THF, the flask was sealed and purged continually with a stream of nitrogen, and the mixture was magnetically stirred for $24 \mathrm{hr}$. The observation was made that soon after the addition of the potassium and naphthalene, the slurry took on a dark olive-green hue. This result was expected according to sternberg's paper, and it was found that if the slurry remained clear, the reagents had been added in the wrong proportions and the subsequent alkylation experiment would be unsuccessful. 
After the $24 \mathrm{hr}$ digestion period, $5 \mathrm{~g}$ of coal was added to the THF slurry directly from a newly opened ampoule. The flask was then resealed and the mixture was magnetically stirred for another $72 \mathrm{hr}$ under a nitrogen blanket. At that time, the flask containing the slurry was removed from the magnetic stirrer, and any undissolved lumps of potassium were removed from the slurry using a metal spatula. A mixture of $10 \mathrm{ml}$ of ethyl iodide in $30 \mathrm{ml}$ of THF was then added drop-wise over a 30 minute period while the flask was stirred. Once the drop-wise addition had been completed, the flask was magnetically stirred for $2 \mathrm{hr}$.

The mixture in the flask was then roto-evaporated to remove a majority of the THF. The coal residue was then transferred to centrifuge tubes where it was slurried with methanol and then centrifuged at high speed for $30 \mathrm{~min}$. The methanol was decanted off, and the slurrying and subsequent centrifugation were repeated three more times to insure that the ethyl iodide had been completely washed away.

The remaining treated coal was then extracted with water using a soxhlet extractor for $24 \mathrm{hr}$ in order to remove any remnant water soluble reagent ions. The treated coal was dried in a vacuum oven overnight at $50^{\circ} \mathrm{C}$ at a vacuum of less than 10 torr, followed by further drying at $100^{\circ} \mathrm{C}$ at a high vacuum (less than 0.1 torr) for $24 \mathrm{hr}$. The alkylated 
coal sample was then transferred to a sample jar and stored in a vacuum desiccator for future use.

\section{3 oxygen Alkylation}

Coal pretreatment via oxygen alkylation (0-alkylation) was conducted using the method first developed by Liotta (3). Coal was 0-ajkylated in batches of 5, 10, or $20 \mathrm{~g}$ and the treated coal samples were used promptly in liquefaction studies so as to minimize storage time after alkylation.

To alkylate $5 \mathrm{~g}$ of raw, undried coal, $120 \mathrm{ml}$ of THF was added to a round-bottomed, three necked flask which was magnetically stirred. Fresh coal was slowly added to form a coal-THF slurry A mixture of 40 percent aqueous tetrabutyl-ammonium hydroxide was then added drop-wise until the pH of the slurry was neutral ( $\mathrm{pH}=7.0)$. The slurry was stirred for $2 \mathrm{hr}$ under a nitrogen blanket, at which tim. methyl iodide was added to the flask in a molar amount equal to twice the number of moles of tetrabutylammonium iodide added previously. The slurry was then stirred overnight under a nitrogen blanket.

The slurry was roto-evaporated under vacuum in order to remove all of the volatiles, leaving only alkylated coal behind. The pretreated coal was soxhlet extracted with water for $24 \mathrm{hr}$ in order to remove all traces of water sol- 
uble reagents. The extracted coal was dried overnight in a vacuum oven at 50 oc and a vacuum of less than 10 torr, followed by subsequent high vacuum drying at $100{ }^{\circ} \mathrm{C}$ for another $24 \mathrm{hr}$ at a vacuum of less than 0.1 torr. The 0-alkylated coal was bottled and stored in a vacuum desiccator for future use.

\subsection{Chlorine Catalyst/Mild Alkylation Pretreatment}

For pretreatment by catalyst dispersion, the procedure developed by Armstrong (4) was used as a guideline. Depending upon the quantity of coal needed, the quantity of coal pretreated in any one batch varied between $5 \mathrm{~g}$ and $20 \mathrm{~g}$. As stated in the previous two pretreatment procedures, the recipe developed was for $5 \mathrm{~g}$ of raw coal.

For each $5 \mathrm{~g}$ of coal pretreated, $40 \mathrm{ml}$ of methanol and $0.40 \mathrm{ml}$ of concentrated hydrochloric acid were mixed together in a three necked, round bottomed flask. The coal sample was then slowly added to the methanol/hydrochloric acid solution and the slurry was magnetically stirred for 3 hr. Next, the slurry was roto-evaporated, removing the majority of the methanol from the coal. The coal sample was then dried at $50^{\circ} \mathrm{C}$ in a vacuum oven overnight at a vacuum of less than 10 torr, followed by vacuum drying at $100{ }^{\circ} \mathrm{C}$ for $24 \mathrm{hr}$ under a vacuum of less than 0.1 torl. The pre- 
treated coal was then transferred to a sample jar, and stored in a vacuum desiccator for future use.

\section{COAL LIQUEFACTION MEASUREMENTS}

\subsection{Equipment Description}

Reactivity enhancement of the pretreated coals was monitored by measuring coal conversion to THF soluble products in a pair of microautoclave tubing bomb reactors. Two identical reactors were built and configured so that two liquefaction experiments could be conducted simultaneously under the same reactivity conditions. This set-up assured that the only true variable between the two liquefaction runs was the pretreatment method used for the coal being liquefied within the tubing bomb reactors; all other variables such as reaction time and temperature would be exactly matched.

Each of the reactors consisted of a body constructed from a 5" length of 1/2" O.D. 316 stainless steel tubing which was sealed on the bottom with a Swagelock 1/2" nut and end plug, as shown in Figure 1. The top of the reactor body consisted of a Cajon VCR female gland fitting welded to the tubing body. The fitting was designed for repeated sealing by means of a sacrificial nickel gasket. All welding of the stainless steel components was performed by Russell D. White, of Boulder, Colorado. 
FIGURE 1

Liquefaction Reactor Assembly

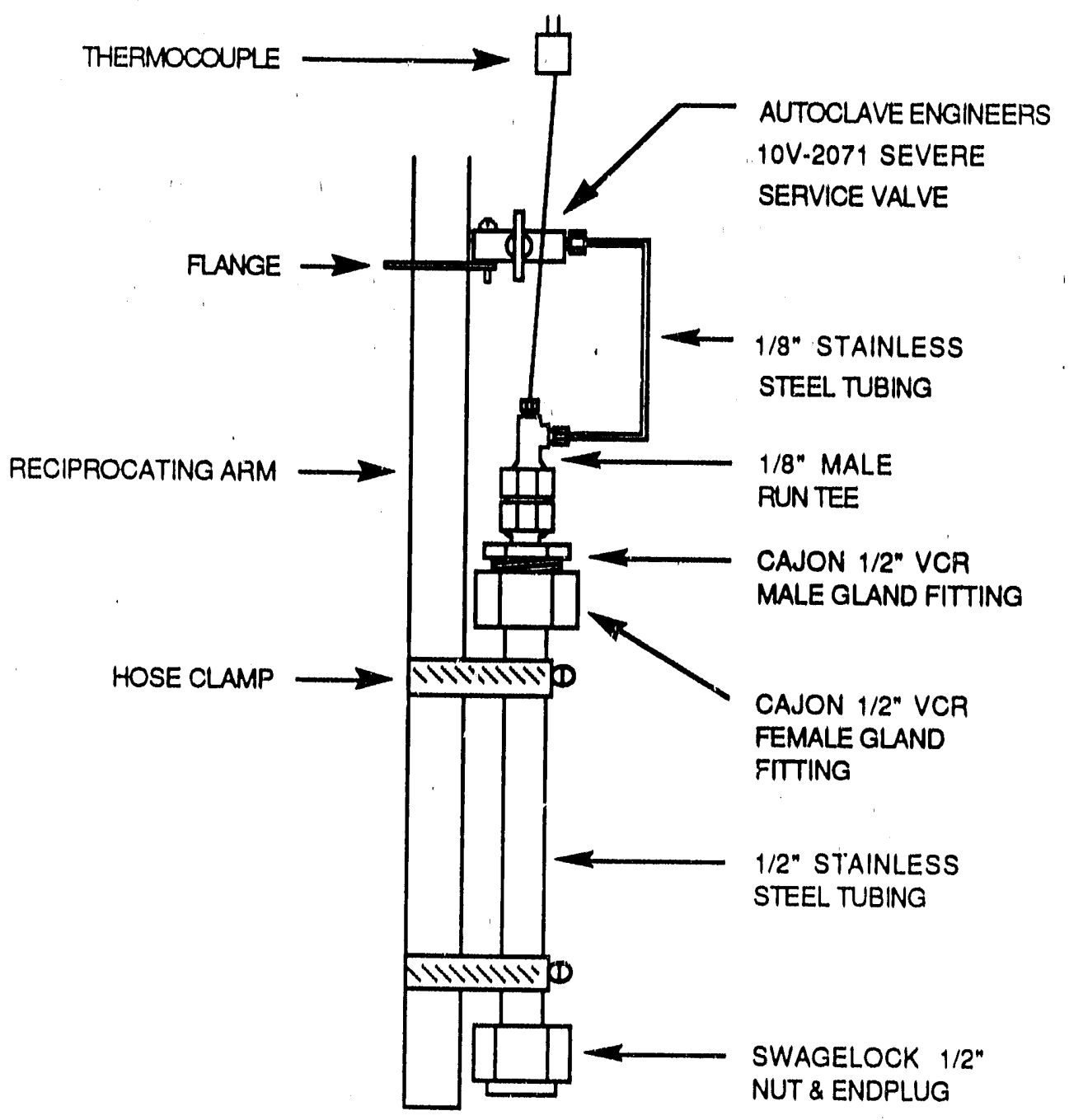




\section{FIGURE 2}

Liquefaction Reactor system

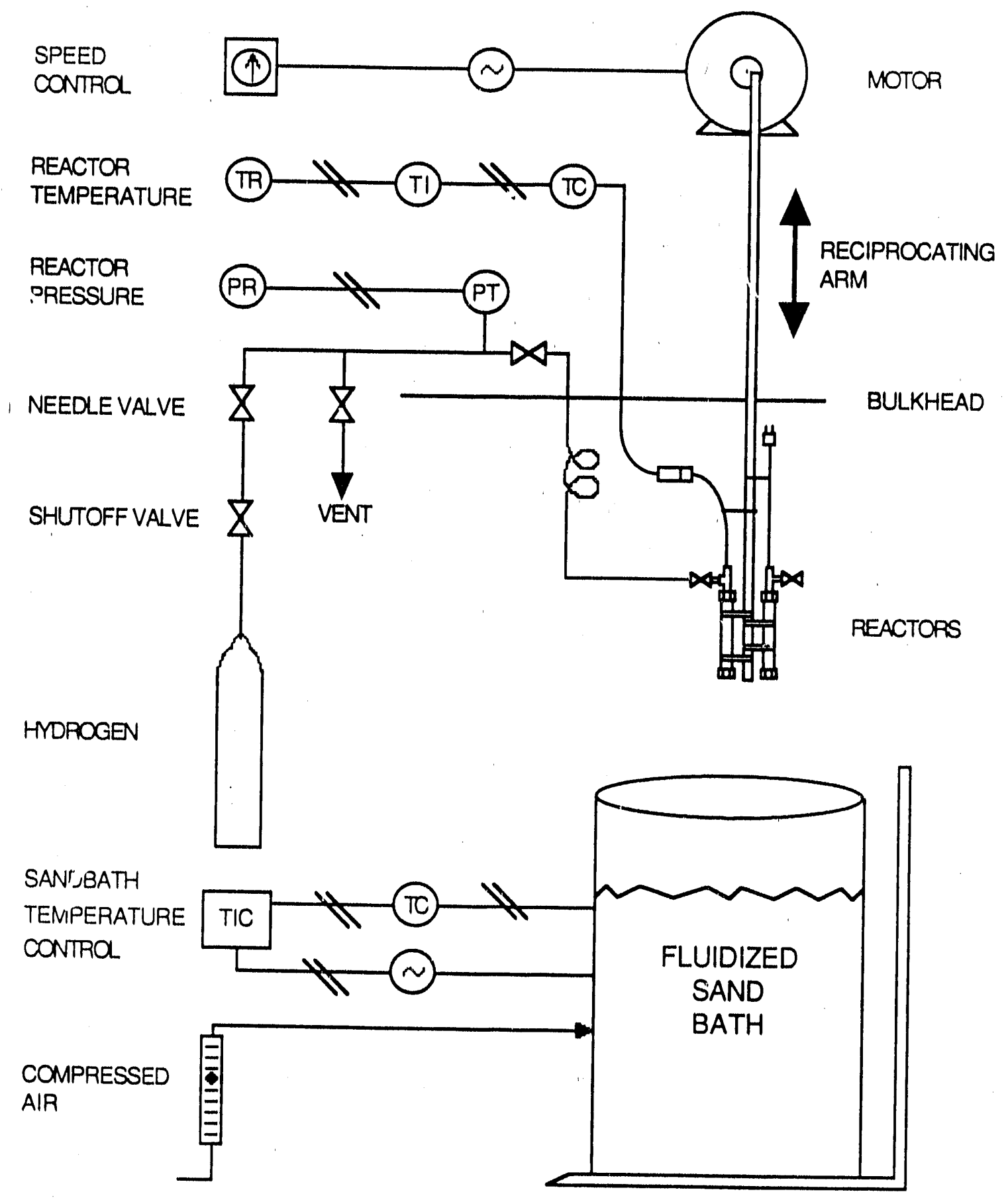


gas delivery system.

Heating the two reactors was accomplished with the use of a Tecam model SBL-20 fluidized sand bath which was positioned on an adjustable hoist below the reciprocating arm. The hoist could be raised or lowered as needed, giving good control over the exact amount of time the reactors were immersed in the sand bath. Each reactor's thermocouple was connected to the thermocouple readout, which provided a continuous temperature reading of the reactor contents during the liquefaction run. Initially, both reactor thermocouples were connected during the liquefaction runs. It was soon observed that the temperature between the two reactors never varied by more than $1{ }^{\circ} \mathrm{C}$, so subsequent runs used a thermocouple readout from only one of the reactors and assumed that this single temperature reading was representative of the internal temperature of both reactors.

During the experimental program, a new pair of reactor heads and ten additional reactor bodies had to be fabricated. A question arose as to whether or not the replacement reactor components would impart a catalytic wall effect to the liquefaction process because of the new stainless steel components. The new reactor components were used in parallel with the old reactor components for three baseline runs where the contents of both reactors were identical. 


\section{TABLE V}

Liquefaction Conversions for Old and New Reactors

\begin{tabular}{|c|c|c|c|c|c|}
\hline \multirow{2}{*}{ COAL } & \multirow{2}{*}{ SOLVENT } & \multirow{2}{*}{$\begin{array}{c}\text { REACTION } \\
\text { TEMP } \\
\left(\begin{array}{c}\text { C })\end{array}\right.\end{array}$} & \multirow{2}{*}{$\begin{array}{c}\text { REACTION } \\
\text { TIME } \\
\text { (Min) }\end{array}$} & \multicolumn{2}{|c|}{$\begin{array}{l}\text { THF COAL } \\
\text { CONVERSION } \\
\left(\begin{array}{ll}\text { WEIGHT } & \%\end{array}\right)\end{array}$} \\
\hline & & & & $\begin{array}{l}\text { OLD } \\
\text { REACTOR }\end{array}$ & $\begin{array}{c}\text { NEW } \\
\text { REACTOI }\end{array}$ \\
\hline IYODAK & DHP & 425 & 5 & $66.2 \%$ & 66.2 \\
\hline WYODAK & $A-8$ & 425 & 5 & $29.6 \%$ & 30.9 \\
\hline ILL. \# 6 & DHP & 350 & 30 & $83.6 \%$ & 82.6 \\
\hline ILL. \#6 & DHP & 425 & 5 & $89.2 \%$ & 89.9 \\
\hline LL. \#6 & $A-8$ & 425 & 5 & $45.5 \%$ & 43.5 \\
\hline
\end{tabular}


properly sealed, and the valve on the reactor assembly was closed. If a continual pressure drop was observed, applying liquid leak detector to the joints of the reactor assembly usually divulged the location of the leak. Once the leak was sealed, the reactor was hooked up again, and repressurized until it was properly sealed. After the reactor valve was closed, the pressurized reactor was removed from the system and reweighed to estimate the mass of hydrogen added to the reactor. The second reactor was then loaded, pressurized and weighed following the same procedure.

once both reactors were loaded, they were re-attached to the reciprocating arm using adjustable hose clamps. The reactor valves were also secured to the arm by means of a horizontal flange around the arm to which bolts from the valve bodies were attached. The thermocouple was then attached to the reciprocating arm by means of a short length of wire. If any part of either reactor assembly exhibited excessive play, the loose part was reattached and tightened prior to the start of the run.

At this point, the reciprocating mutor was started, the sand bath hoist was raised, immersing the reactors in the fluidized bath, and the timer was started. The time required for the reactor contents to rise to reaction temperature was usually less than $2 \mathrm{~min}$. for low severity runs 
$\left(350{ }^{\circ} \mathrm{C}\right)$ and less than $3 \mathrm{~min}$. for high severity runs $(425$ ${ }^{\circ}$ ). At the end of the desired reaction time, the sand bath was lowered and the reactors were cooled with compressed air followed by immersion into a cold water bath. The reactors were then detached from the reciprocating arm, and blown free of water and fluidizing sand with compressed air. At this point, each reactor was weighed, degassed under a hood, or into an appropriate gas sampling cylinder, and reweighed to estimate the mass of gas removed.

\subsection{Liquefaction Product Recovery}

In order to calculate the extent of coal liquefaction based upon conversion to tetrahydrofuran soluble products, all reaction products had to be quantitatively recovered from the reactor asselnbly and washed with tetrahydrofuran (THF) $\quad$ This enabled the use of THF as wash solvent for cleaning the reactor head and body. The reactor body was repeatedly rinsed and agitated with THF, and the THF/product slurry was collected into a pre-weighed centrifuge tube. This process was repeated with both the body and if necessary, the head of the reactor, until any THF removed from the reactor parts remained clear. The centrifuge tubes for each reactor were then filled to equal levels with additional THF, and centrifuged at $2000 \mathrm{rpm}$ for $15 \mathrm{~min}$. Excess 
THF was decanted from each of the tubes and fresh THF added. The tubes were then sonically agitated in a water bath for $10 \mathrm{~min}$. to promote complete mixing of the fresh THF with the centrifuge residue. This centrifugation process was repeated until THF decanted from the tubes remained clear. Three washes with THF were usually sufficient to obtain clear THF upon decantation. The centrifuge tubes and each clean reactor body were then placed in a $125^{\circ} \mathrm{C}$ oven overnight, to remove all residual traces of THF.

once the reactor body and the centrifuge tubes were dried, they were removed from the oven, and were allowed to cool. The centrifuge tubes were weighed in order to determine the mass of THF insoluble products. The reactor body was also weighed, and any gained weight was assumed to be due to traces of THF insoluble material left behind from the reactor cleanout process. For the majority of liquefaction experiments, the weight gain of the reactor body was zero, indicating that the reactor had been thoroughly rinsed. If any weight gain was recorded, it was added to the weight of THF insolubles collected in the centrifuge tubes.

\section{MOISTURE FRACTION DETERMINATION}

The amount of moisture present in the feed coal was determined by taking a representative sample of the coal 
charged to the reactor, and performing a weight loss upon drying analysis. Weight lost upon drying was determined by weighing a sample of coal placed in a crucible of known mass. The crucible was placed in a $125^{\circ} \mathrm{C}$ oven overnight, removed, and cooled in a vacuum desiccator. The crucible was reweighed and the loss in weight upon drying was divided by the starting weight of coal, giving a weight fraction loss upon drying which was assumed to be moisture loss. The weight loss analysis was performed in duplicate in order to minimize error in the moisture content calculation; it was found that the two samples always agreed within 2.0 wt\%. The moisture content of the THF insoluble material was assumed to be zero due to the drying of the THF insoluble material overnight at $125^{\circ} \mathrm{C}$.

\section{ASH FRACTION DETERMINATION}

Coal conversion for all samples liquefied or coprocessed is calculated on a moisture and ash free basis, resulting in the need to have an accurate measurement of the ash fraction in each coal. The ash fractions of all coal samples used in the study are listed in Table VI. Ash fractions for the untreated coals were as determined by Argonne National Laboratories, which supplied the coal used in this study (1). Ash fraction of pretreated coal samples were 
determined by Huffman Laboratorles, of Golden, Colorado. 
TABIE VI

Ash Fraotions of Untreated and Pretreated Coals

on A Moisture Free Basis

PRETREATMENT METHOD >

$\begin{array}{cccccc}\text { COAL } & \text { UNTREATED } & \text { CC/MAP } & \text { LIOTTA } & \text { STERNBERG } & \text { i } \\ \text { WYODAK } & 0.0877 & 0.0783 & 0.0656 & 0.1268 & \text { s } \\ \begin{array}{c}\text { ILLINOIS } \\ \text { \#6 }\end{array} & 0.1548 & 0.1590 & 0.1434 & 0.1487 & 1 \\ & & & & & 1\end{array}$

CC/MAP: Chlorine Catalyst/Mild Alkylation Pretreatment LIOTTA: Oxygen Alkylation Pretreatment

STERNBERG: Reductive Alkylation pretreatment 


\section{TABLE VII}

\section{Number of Alkyl Groups Added To Parent Coal}

By Mild Pretreatment

PRETREATMENT METHOD

(alkyl groups/100 C atoms)

$\begin{array}{lccc}\text { COAL } & \text { CC/MAP (1) } & \text { STERNBERG (2) } & \text { LIOTTA (1) } \\ \text { WYODAK } & 1.5 & 5.7 & 8.0 \\ \text { ILL. \#6 } & --- & 6.7 & 4.7\end{array}$

(1) methyl group addition

(2) ethyl group addition 


\subsection{Oxygen Alkylation}

oxygen alkylation using the Liotta procedure resulted in the addition of 8.0 methyl $\left(\mathrm{CH}_{3}\right)$ groups/100 C atoms for the subbituminous coal and 4.7 methyl groups/100 C atoms for the bituminous coal. Subbituminous coal has a higher oxygen content with more oxygen functionalities present within the coal as compared to the bituminous coal. Because 0-alkylation is oxygen selective, the coal with more oxygen undergoes a greater extent of alkylation during the Liotta pretreatment process.

\subsection{Reductive Alkylation}

Reductive alkylation using sternberg's procedure added 5.7 ethyl groups/100 C atoms to the subbituminous coal and 6.7 ethyl groups $/ 100 \mathrm{C}$ atoms to the bituminous coal. Reductive alkylation is a non-selective alkylation occurring primarily at polar chemical sites within the coal, which is confirmed by the small difference in the extent of alkylation for the coals of different rank. Some oxygen alkylation does occur because of the polar nature of most oxygen functionalities, but its effect is not significant when compared to the reductive alkylation of carbon sites in the coal structure. 


\subsection{Chlorine Catalyst/M11d Alkylation Pretreatment}

\subsubsection{Extent of A.1kylation}

Selected coals which were pretreated via the chlorine catalyst/mild alkylation pretreatment (CC/MAP) procedure were also subjected to ultimate analysis in order to determine the extent of alkylation during pretreatment. The CC/MAP procedure resulted in the addition of 1.5 methyl groups/100 C atoms to the subbituminous coal. This small extent of alkylation is indicative of the very mild reaction conditions used in this procedure. Although alkylation does take place, the magnitude of alkyl group incorporation is much lower than in the other procedures where alkylation is the sole means of coal pretreatment. The extent of alkylation attained in the bituminous coal using this procedure was not measured.

\subsubsection{Extent of Chlorine Incorporation}

Untreated Wyodak coal has a chlorine content of $0.18 \%$ by weight, but the chlorine content of the pretreated coal was found to be $2.41 \%$ by weight. This shows that pretreatment via the chlorine catalyst/mild alkylation procedure does result in the incorporation of a significant amourt of chlorine into the coal structure. During liquefaction, chlorine is possibly converted to hydrochloric acid (HCl) which acts 
as a strong hydrooracking oatalyst. Although the amount of chlorine initially present is amall, the subsequent HCI formed may have a significant impact upon coal conversion under Iiquefaction conditions. The amount of chlorine present in pretreated Ilinols \#6 coal was not measured, but may be assumed equivalent in proportion to the concentration incorporated into the Wyodak coal samples.

\section{INTRINSIC THF SOLUBILITY OF UNTREATED AND TREATED COALS}

In order to use coal conversion to THF soluble products as a measure of coal reactivity, the intrinstc THF solubilIty of both untreated and pretreated coals hac to be determined. The intrinsic THF solubility of each coal was determined on a molsture and ash free (MAF) basis (Table VIII). These solubilities were determined by adding a known mass of coal to a centrifuge tube and applying the same THF extraction process used in Section 4.3 of the Experimental Procedure. The fraction of the original coal sample lost to THF extraction represented the intrinsic THF soluble portion of the coal.

The difference between the intrinsic THF solubility of a raw coal and the same coal after pretreatment reflects the effect of the pretreatment process upon the coal. Untreated Wyodak coal had an intrinsic THF solubility of 1.6 wt. 


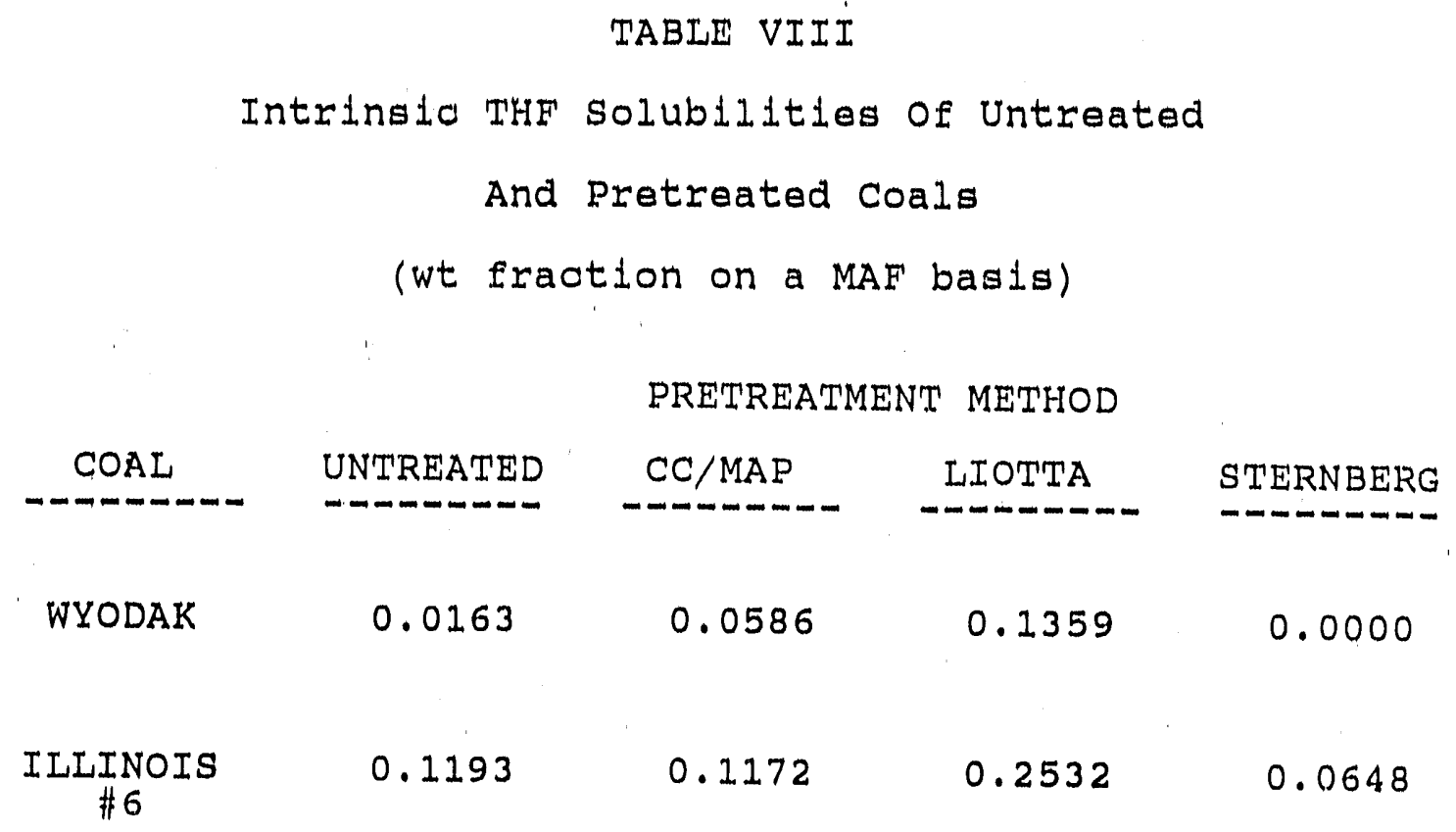

CC/MAP: Chlorine Catalyst/M1ld Alkylation pretreatment LIOTTA: Oxygen Alkylation Pretreatment

STERNBERG: Reductive Alkylatior. Pretreatment 
but after pretreatment using the Liotta procedure, the intrinsto THF solubility was 13.6 wt. $\frac{\circ}{6}$. The difference between these two values represents the effect of Llotta's oxygen alkylation upon wyodak coal prior to liquefaction. The effect of sternberg's method upon the treated coal cannot be determined, because sternberg's procedure involves rinsing the coal with THF during the alkylation procedure. Any increase in THF solubility brought about by the pretreatment is washed away by THF. Table VIII reflects this fact, where the intrinsic THF solubility of both wyodak and Illinois \#6 coal after pretreatment with sternberg's procedure is lower than the THF solubility of the untreated coal.

\section{CALCULATION OF COAL CONVERSION}

Coal reactivity was based upon the conversion of THF insoluble coal to THF soluble products on a moisture and ash free basis using the following equation:

where:

$$
\text { THF Coal Conversion }=\frac{(I-\check{O})}{I} * 100 \%
$$

$$
\begin{aligned}
I= & (g \text { of coal in }) *(1-a s h \text { fraction }) *(1-\text { moisture fraction }) \\
& *(1-\text { intrinsic } T H F \text { soluble fraction of feed coal) } \\
O= & (g \text { of } \mathrm{THF} \text { insoluble material recovered) } *(1-\text { fraction ash) }
\end{aligned}
$$

Intrinsic THF soluble matter in the feed coal was estimated 
using the intrinsio THF solubilities shown in Table VIII. Because intrinsic THF solubilities are accounted for, the conversion equation above estimates the effect of pretreatment upon coal reactivity under liquefaction or coprocessing conditions.

\section{REACTIVITY PARAMETER MATRIX}

Coal conversion results for the reactivity parameter matrix studied are shown in Table IX. The non-alkylated THF coal conversions are for liquefaction/co-processing of the untreated coal samples at each set of reactivity conditions. For each of the pretreatment methods listed (including no pretreatment), the THF coal conversion represents a mean value of repeated reactivity experiments. The percent increase in conversion shown in Table IX was calculated with respect to the corresponding untreated coal conversion.

The raw data used to generate the values listed in the reactivity parameter matrix can be found in Appendix A. Mean values were calculated from repeated trials for each set of reactivity conditions. In situations where repeated trials showed a large difference in the coal conversion values, additional trials at the same conditions were conducted. All trials were then used to calculate an estimate of the mean. 
TABLE IX

Completed Reactivity Parameter Matrix

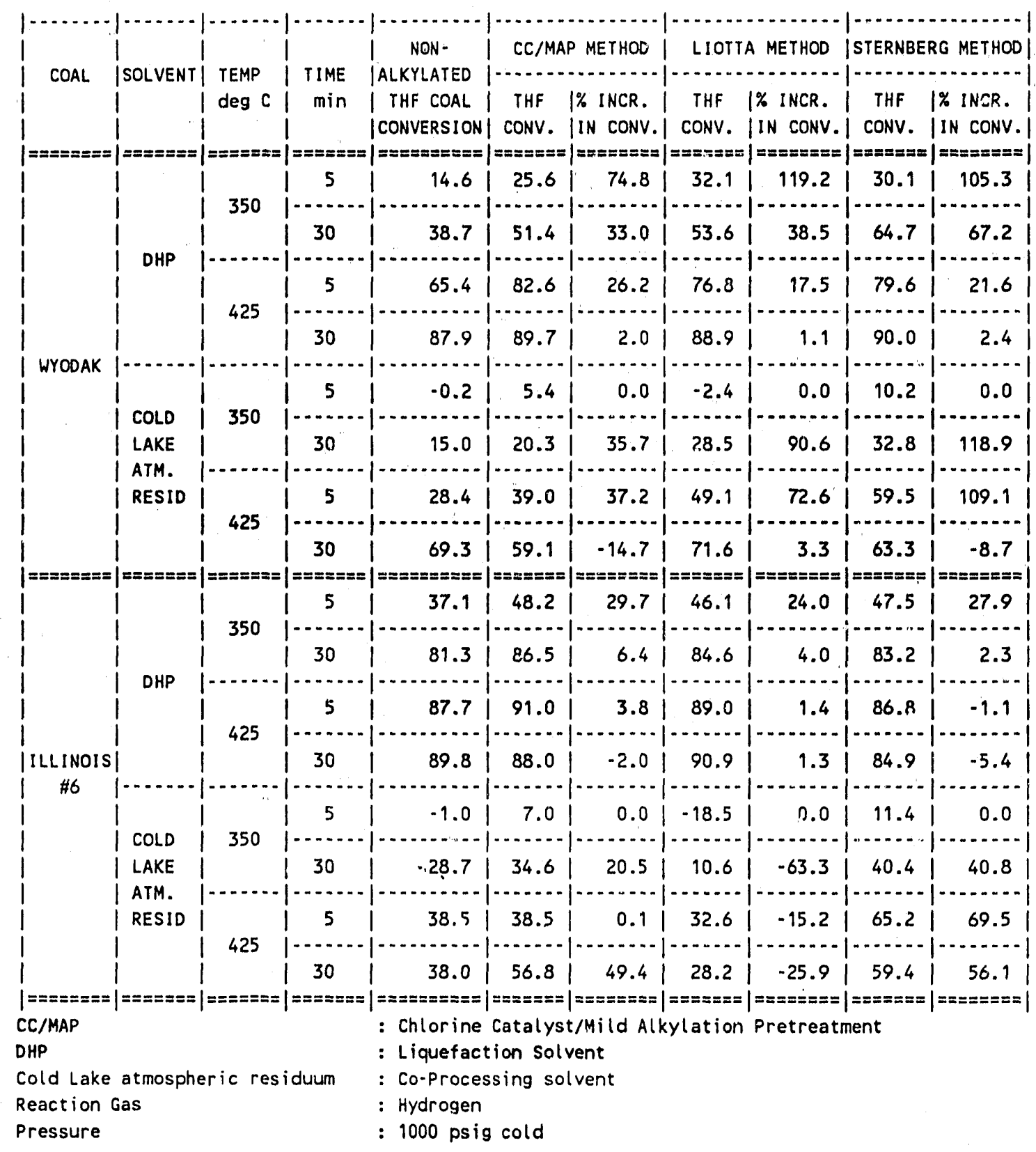


Trials which were suspected as outlying data points were subjected to a one tailed t-test. Mean coal conversion was calculated without the suspect point, and the probability of the conversion being less or equal than the suspect point, given the "new" mean conversion, was calculated. If this probability was $<5$ wt. $\%$, then the suspect point was not used in the estimate of the mean, and the "new" mean conversion was used.

A five factor analysis of variance (ANOVA) was conducted using reactivity runs for the untreated and the CC/MAP pretreated coals at all combinations of reactivity conditions (Appendix B). It was found that the standard deviation between repeated trials at any one set of conditions was $+/-$ 4.3 wt. $\%$. This means that the amount of random error between trials for any set of conditions is $+/-4.3$ wt. $\%$. Although only data from the untreated coal and chlorine catalyst/mild alkylation treated coal samples were used in this analysis, it is assumed that the random error calculated in the analysis of variance also applies to runs made using the Liotta and sternberg treated coals.

All values used in the subsequent discussion of liquefaction and co-processing reactivity experiments are taken from mean values tabulated in Table IX. 


\section{LIQUEFACTION REACTIVITY EXPERIMENTS}

Prior to performing liquefaction experiments involving pretreated coal samples, the baseline reactivity data for untreated coal using dihydrophenanthrene (DHP) as a liquefaction solvent was determined. In the following discussion, the different combinations of liquefaction reactivity conditions are divided into two groups: low severity parameter combinatious $\left(350{ }^{\circ} \mathrm{C}\right)$ and high severity parameter combinations $\left(425^{\circ} \mathrm{C}\right)$. The individual contributions of coal rank and reaction time are more easily observed at each level of severity when this distinction is made.

Baseline reactivity data for both low and high severity liquefaction of untreated coal is shown in Figure 3. At both low and high severity conditions, coal conversion is a function of coal rank, with bituminous coal (Illinois \#6) exhibiting a higher conversion to THF solubles than subbituminous coal (Wyodak) for all combinations of time and temperature. These results agree with other coal liquefaction studies where bituminous coal was found to have a higher baseline conversion than subbituminous coal.

At low severity liquefaction conditions reaction time is an important factor, more than doubling the THF conversion of both ranks of coal when the reaction time is increased from 5 to $30 \mathrm{~min}$. Conversion of Wyodak coal increases from 


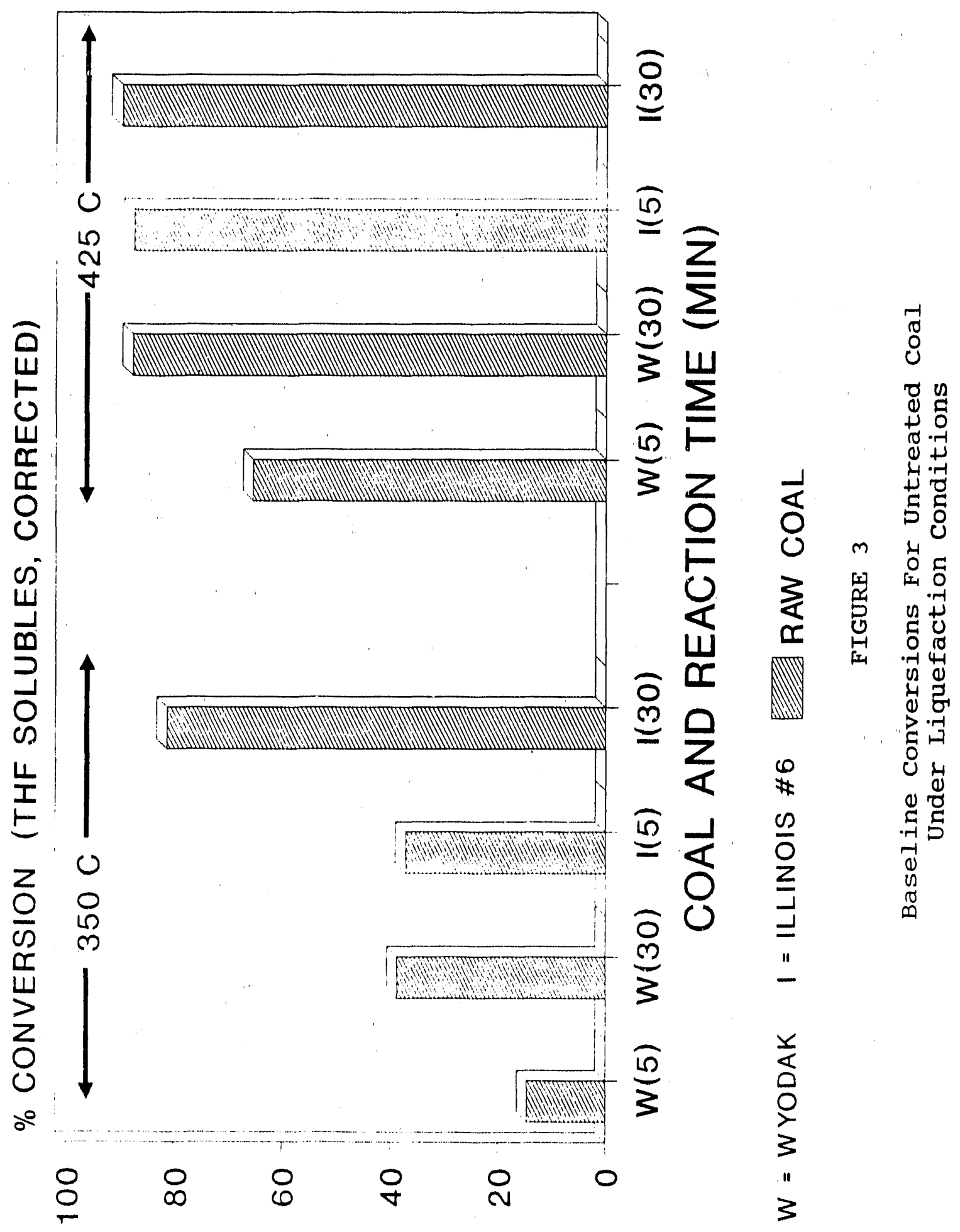


14.6 to $38.7 \mathrm{wt}$. \% while conversion of the Illinols \#6 coal increases from 37.1 to 81.3 wt. $\%$

At high severity liquefaction conditions, Figure 3 shows that the baseline coal conversions for the untreated coals are higher for all coal ranks and reaction times when compared to the conversions observed at low severity. The conversion for the Wyodak coal increases from 65.4 to 87.9 wt. $\%$ as the reaction time is increased from $5 \mathrm{~min}$ to 30 min. The conversion for the Illinois \#6 coal increases from 87.7 to 89.8 wt. $\%$ for the same corresponding increase in reaction time.

This suggests that for high severity liquefaction using DHP as a solvent, the maximum attainable limit for conversion is close to $90 \mathrm{wt}$. \%. The high rank coal approaches this conversion limit after only $5 \mathrm{~min}$ of liquefaction time. Increasing the liquefaction time beyond $5 \mathrm{~min}$ results in a negligible increase in coal conversion. For the low rank coal, the conversion attained in $5 \mathrm{~min}$ of reaction time is 65.4 wt. $\%$. However, when the reaction time is increased to $30 \mathrm{~min}$, conversion of the low rank coal also approaches this conversion limit of about $90 \%$. 


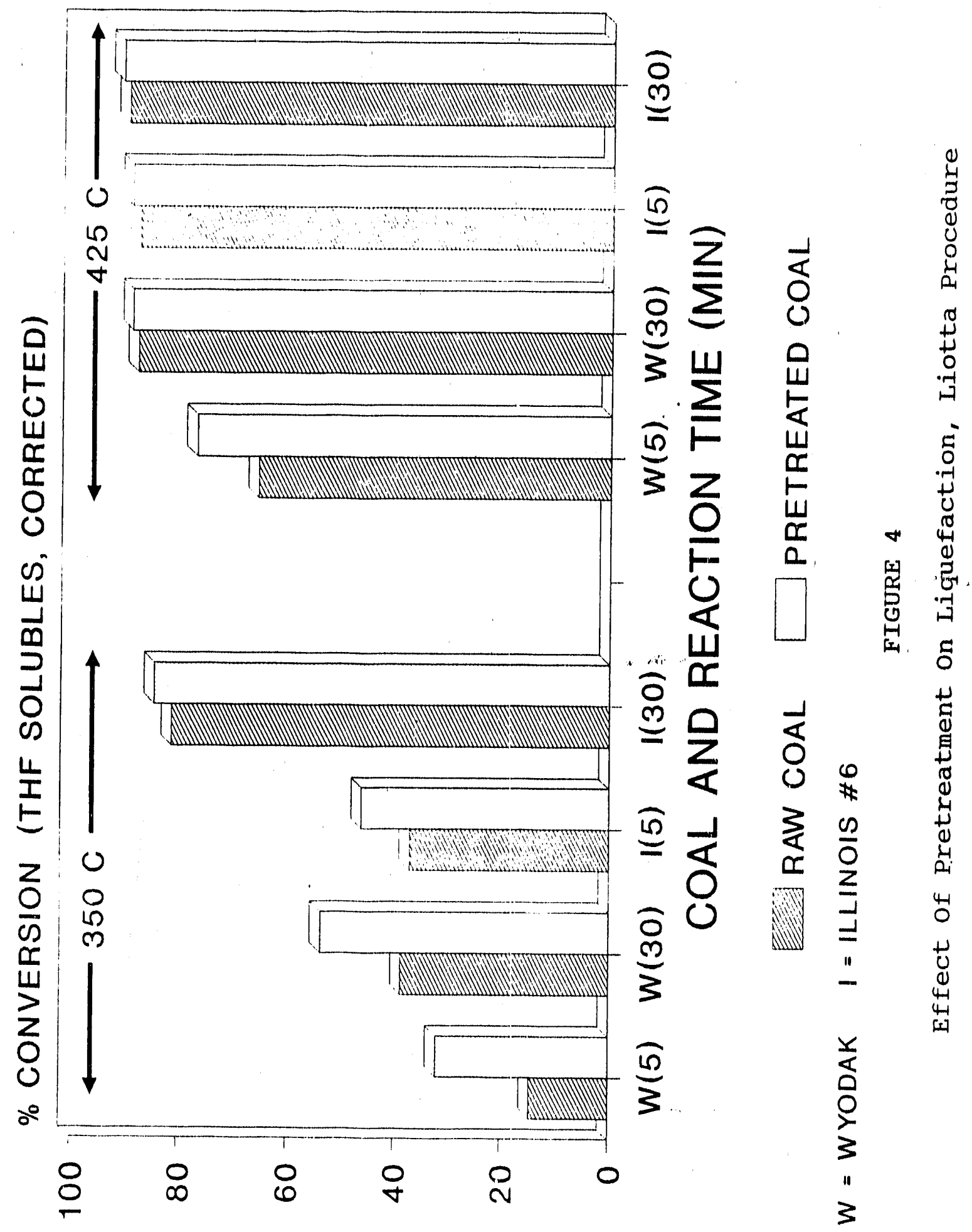


oxygen functionalities which are converted to less polar ether linkages, perhaps preventing the phenolic functionalities from participating in retrogressive reactions. In a model compound study, MoMillen showed that hydroxyl coupling reactions resulted in peroxide bond formation, hence generating reaction products which were highly refractory (5).

$$
\mathrm{R}_{1}-\mathrm{OH}+\mathrm{R}_{2}-\mathrm{OH} \rightarrow-\mathrm{R}_{1}-\mathrm{O}-\mathrm{O}-\mathrm{R}_{2}+\mathrm{H}_{2}
$$

McMilien observed that these coupling reactions were strongly promoted at $400{ }^{\circ} \mathrm{C}$. The formation of these products can be considered representative of the retrogressive reactions observed in low rank coal under certain liquefaction conditions. Even though low severity liquefaction experiments were carried out at a lower temperature $\left(350^{\circ} \mathrm{C}\right)$ than the conditions used by McMillen $\left(400^{\circ} \mathrm{C}\right)$, pretreatment via oxygen alkylation may still result in a greater degree of reactivity enhancement in the low rank coal by chemically altering the coal functionalities which are prone to retrogressive reactions.

High severity liquefaction $\left(425^{\circ} \mathrm{C}\right)$ of coal pretreated with Liotta's procedure shows a lesser degree of reactivity enhancement with respect to the untreated coal as compared to low severity liquefaction (Figure 5). Liquefaction of 


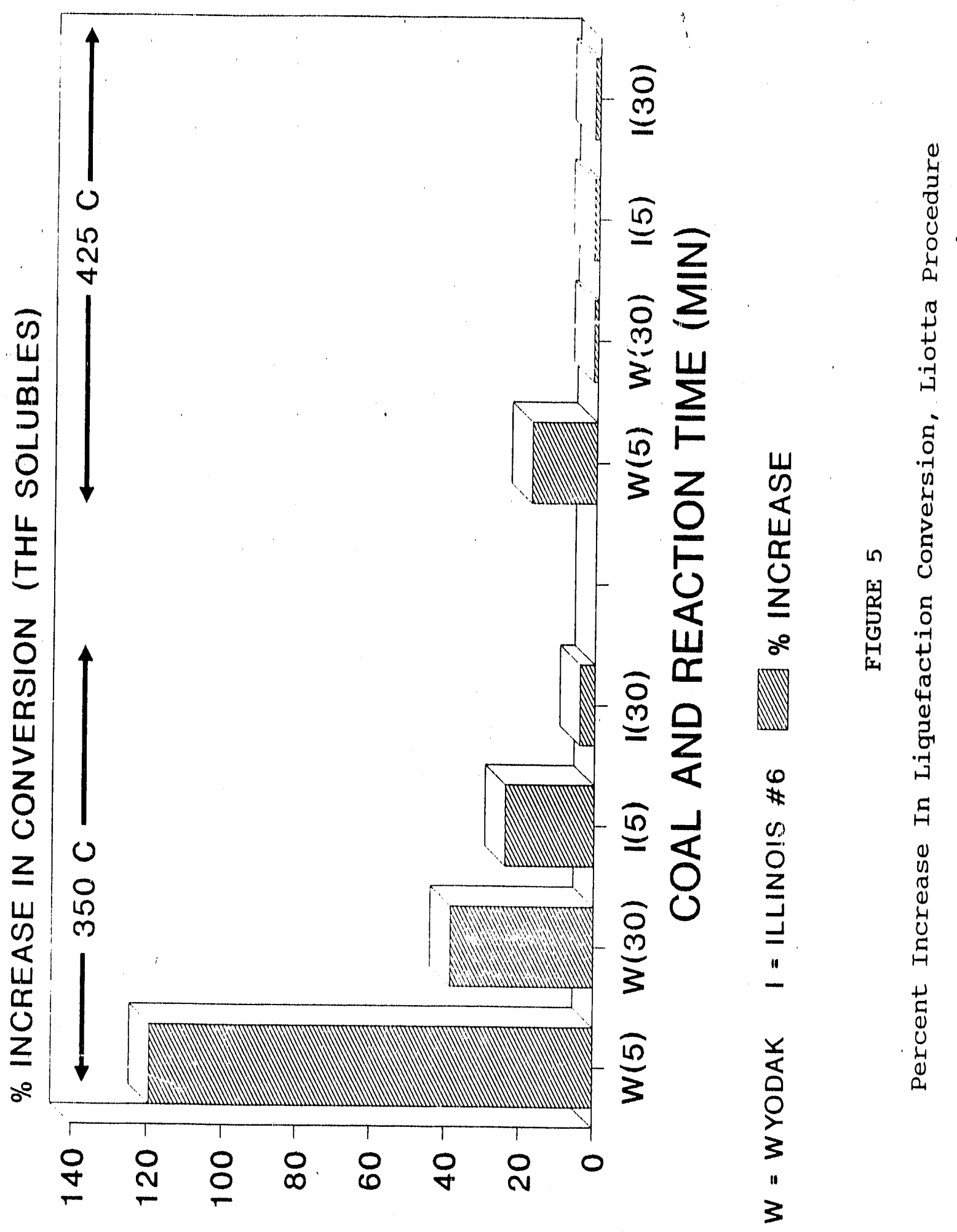


Wyodak coil at $5 \mathrm{~min}$ reaction time was the only case where a significant increase in reactivity relative to the untreated doal was observed with a $17.1 \%$ increase in conversion. Within experimental error, the $30 \mathrm{~min}$ ilquefaction of Wyodak and both ilquefaction times of Ililnois \#G coal resulted in no coal reactivity emhancement.

This result can be attributed, to the fact that at high severity liquefaction conditions the coal conversion is close to the attainable limit. Pretreatment of the feed coal results in a negligible reactivity enhancement because the maximum coal conversion has already been reached. The 5 min liquefaction of the Wyodak coal did result in a significant reactivity increase because the untreated conversion of 65.4 wt. \% was well below the point where the limit of conversion is reached.

\subsection{Reductive Alkylation Liquefaction Experiments}

Data for reactivity studies of coal pretreated using Sternberg's reductive alkylation procedure are shown in Figure 6 along with the baseline coal conversion for each set of reaction conditions. Figure 7 shows the percent increase in conversion for the pretreated coal with respect to the untreated coal for the same sets of reaction conditions. 


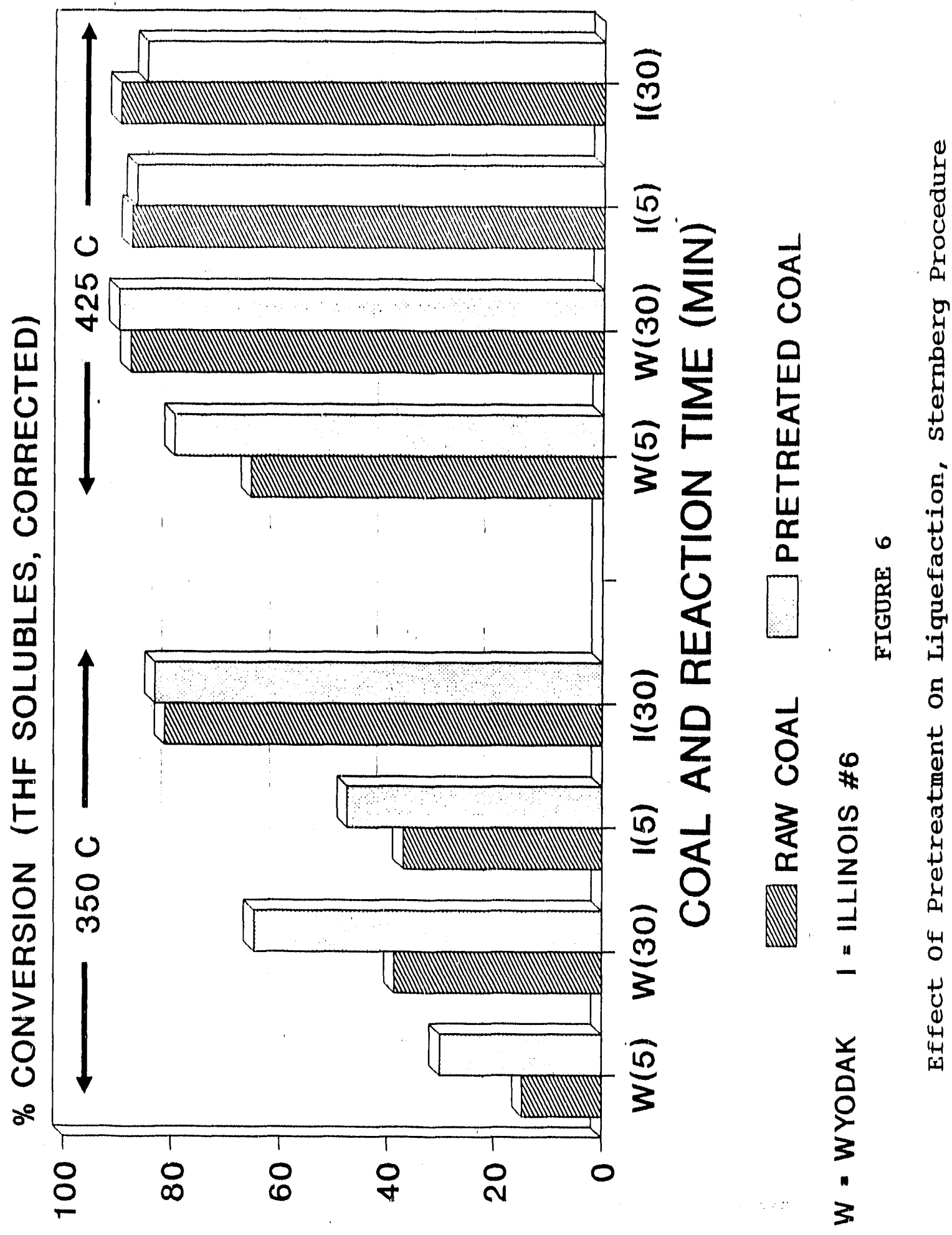




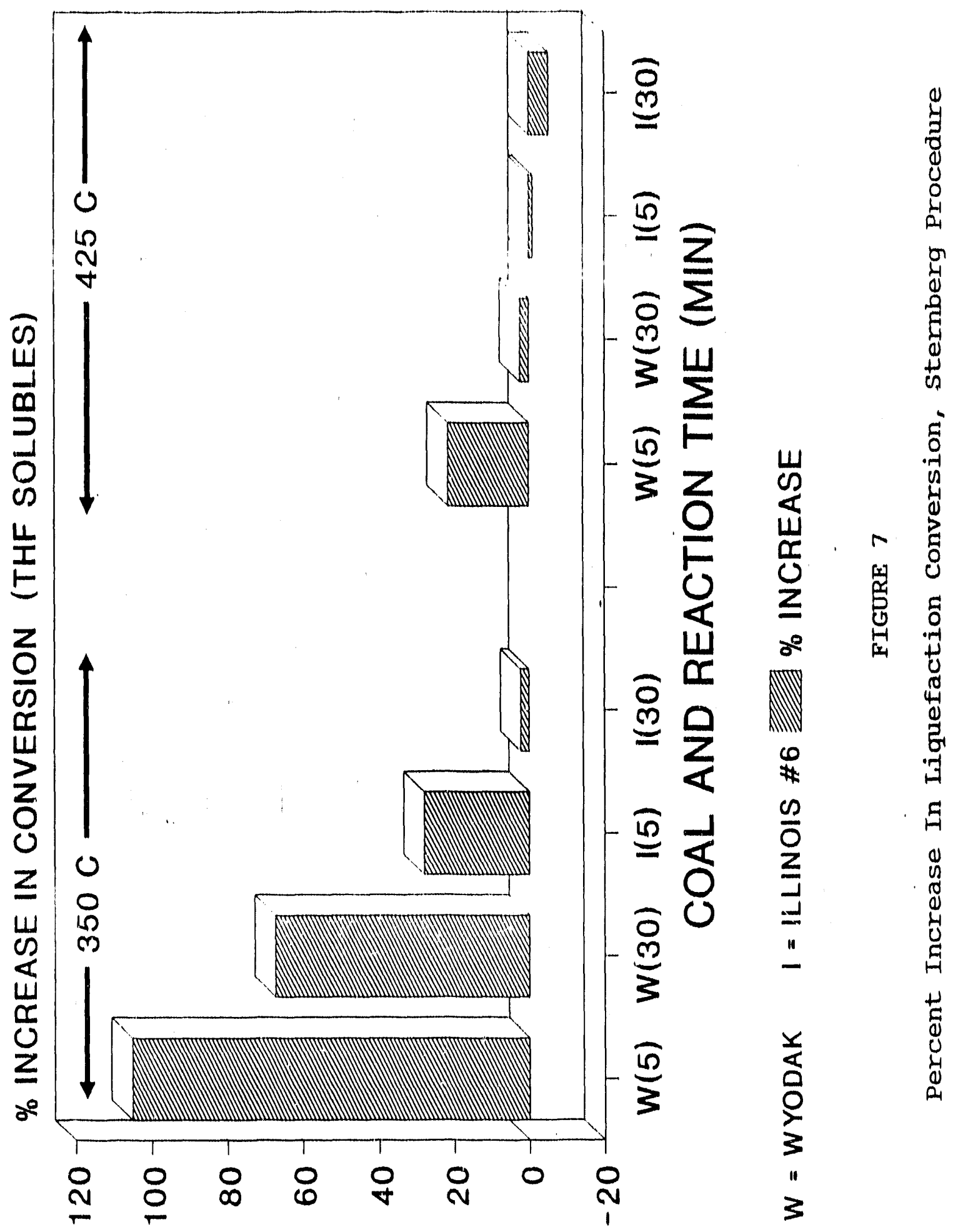


In Figure 7, low severity liquefaction $\left(350^{\circ} \mathrm{C}\right)$ at a reaction time of $5 \mathrm{~m}$ in regults in a $105.3 \%$ increase in oonverston for Wyodak coal while Ilitnols \#G coal shows an increase in conversion of only $27.9 \%$. For a reaction time of $30 \mathrm{~min}$, low severtty 1 lquefaction of wyodak results in a 67.2\% Inarease in conversion while Ilinots \#6 coal shows only a $2.3 \%$ inorease in conversion. For both reaction times, Wyodak doal exhibits the greater perdent increase in conversion when compared to Illinols \#6 coal. The same trend is observed at high severity iquefaction conditions $\left(425^{\circ} \mathrm{C}\right)$. At a reaction time of $5 \mathrm{~min}$, the percent increase in conversion for wyodak coal (21.6\%) is larger than the percent change for Illinois \#6 coal $(-1.1 \%)$. At a reaction time of $30 \mathrm{~min}$, the percent increase in conversion for Wyodak coal (2.4\%) is greater than the percent increase in conversion for Ililnois \#6 coal ( $-5.4 \%)$.

These trends indicate that sternberg's reductive alkylation imparts a higher degree of reactivity enhancement to Wyodak coal than to Illinois \#6 coal for all combinctions of iqquefaction reactivity conditions studied. Since reductive alkylation occurs at polar coal sites, resulting in a mild but non-selective alkylation of the coal, the larger concentration of oxygen functionalities in the Wyodak coal doesn't account for the significantly higher degree of reactivity 
enhancement. Instead, these trends may be due to the fact that the untreated wyodak coal has a lower inherent reactivIty than that seen in the untreated Illinois \#6 coal. Because the untreated wyodak coal has a lower baseline conversion than the untreated IIlinols \#6 coal, pretreatment of both coals by the same non-selective method may result in a more significant reactivity enhancement in the wyodak coal.

\subsection{Chlorine Catalyst/Mild Alkylation Liquefaction Exper=} iments

Liquefaction conversion data for coal samples pretreated with the chlorine satalyst/mild alkylation pretreatment procedure developed by Armstrong are shown in Figure 8 . F'or each combination of reaction conditions, the baseline conversion for the untreated coal is also displayed. The percent increase in conversion for the pretreated coal compared to the baseline conversion for the untreated coal is shown in Figure 9 for all combinations of reaction conditions.

Conversion data for low severity liquefaction conditions $\left(350{ }^{\circ} \mathrm{C}\right.$ ) in Figure 9 indicate that, at both 5 and $30 \mathrm{~min}$ reaction times, Wyodak coal exhibits a larger percent increase in conversion than Illinois \#6 coal. This result again suggests that the lower the baseline conversion of the untreated coal, the more significant the liquefaction 


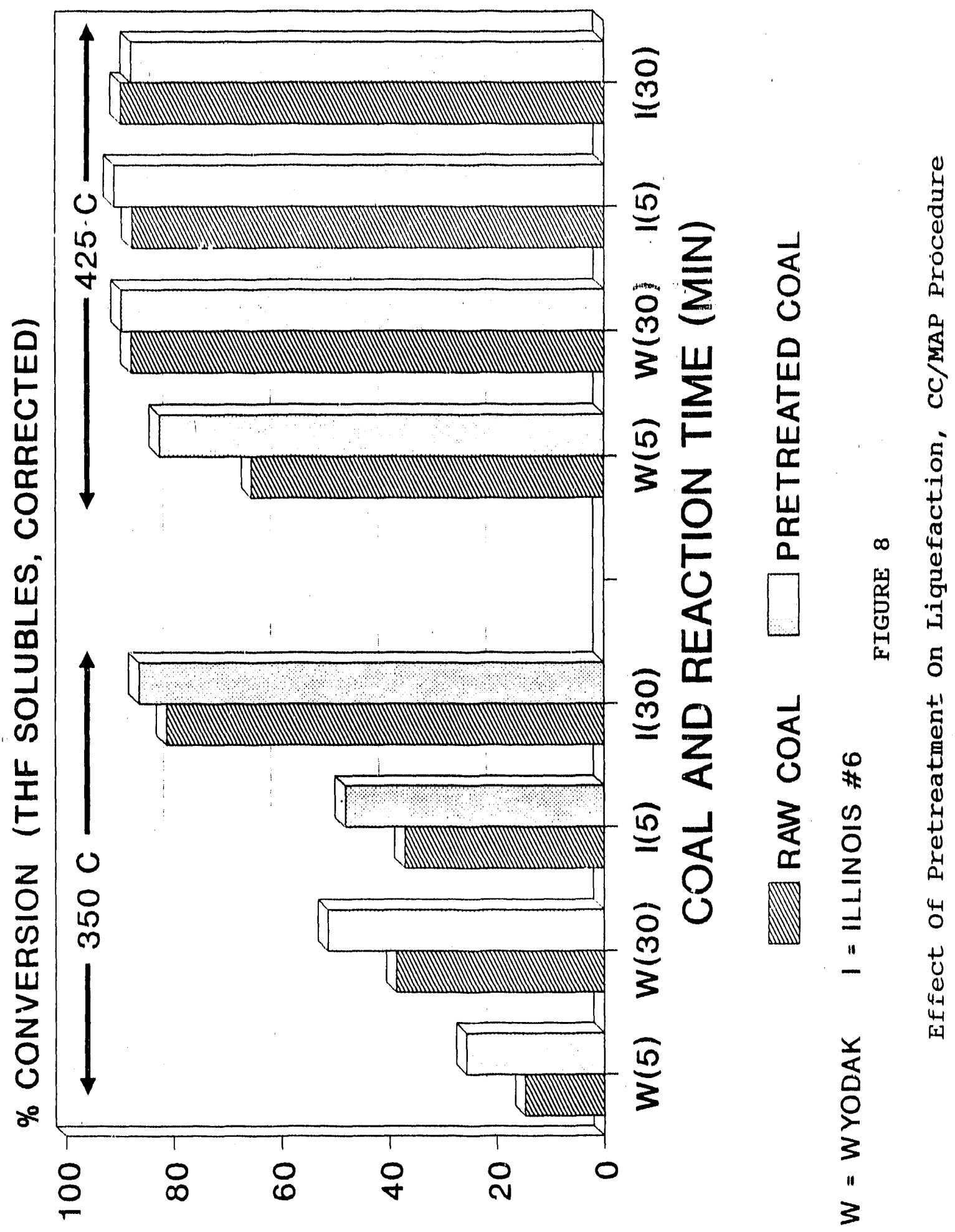




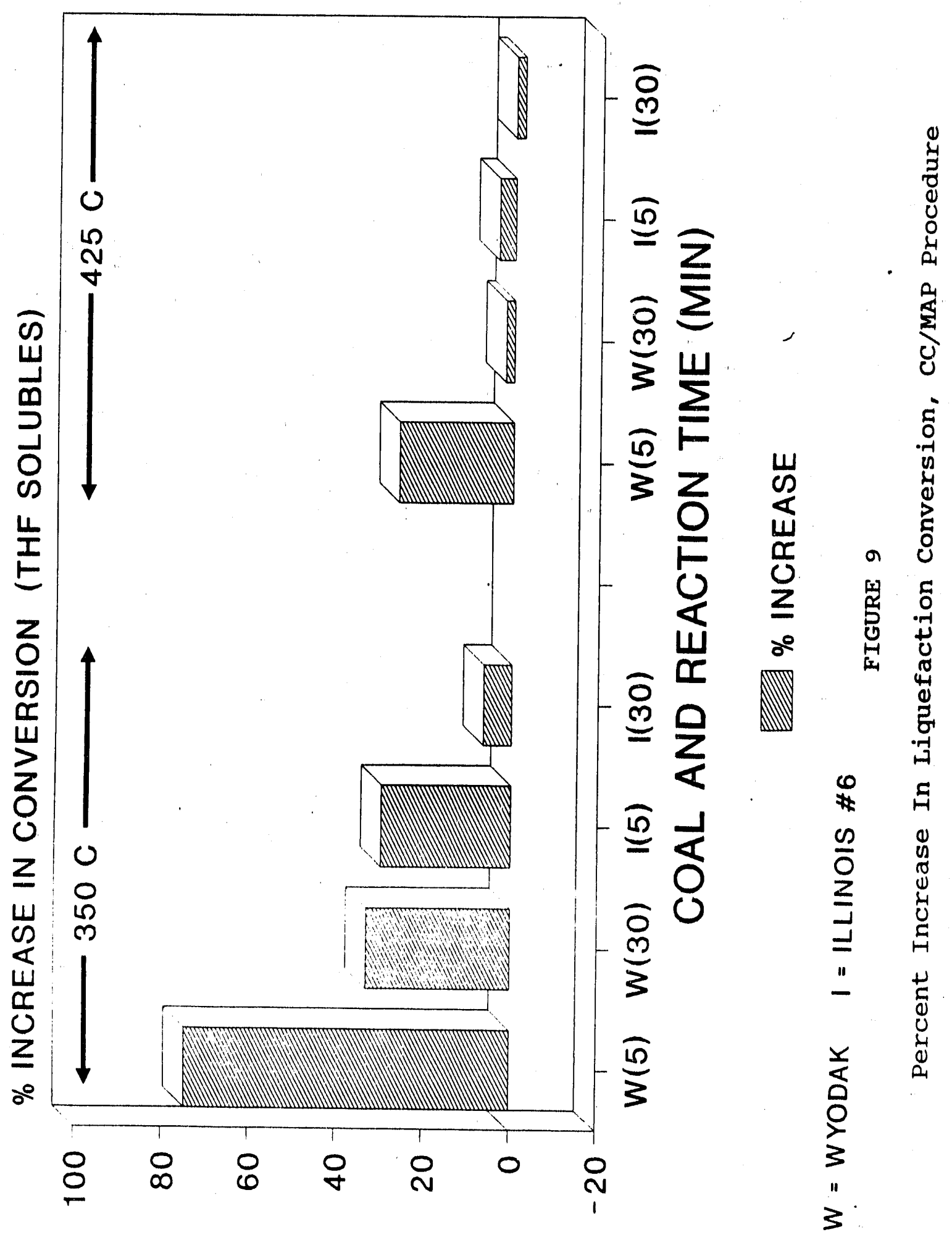


enhancement due to the pretreatment process.

For both Wyodak and Illinois \#6 coal, the percent increase in conversion is larger at $5 \mathrm{~min}$ reaction time than at $30 \mathrm{~min}$ reaction time. This non-linear increase in conversion could be considered a catalytic effect where the activity of $\mathrm{HCl}$ catalyst at short reaction times results in an a high degree of initial reactivity enhancement which is obscured at longer reaction times.

Runs at high severity liquefaction conditions $\left(425{ }^{\circ} \mathrm{C}\right)$ indicate that only wyodak coal at the 5 min reaction time exhibits a significant increase in reactivity enhancement, with a $26.2 \%$ increase in conversion over the untreated baseIine conversion. Within experimental error, conversion levels in the other three reaction combinations are identical. This result indicates that under high severity liquefaction conditions, coal pretreatment imparts no reactivity enhancement because coal conversion is already nearly maximized.

\section{CO-PROCESSING REACTIVITY EXPERIMENTS}

Conversion to THF soluble products was determined for the untreated coal to determine the baseline coal conversion for each combination of co-processing reaction conditions. Mildly hydrotreated Cold Lake atmospheric residuum was used 
as the co-processing solvent in all experiments. In the following discussion, the different combinations of coprocessing reactivity experiments are divided into low and high severity $\left(350^{\circ} \mathrm{C}\right.$ and $\left.425^{\circ} \mathrm{C}\right)$ conditions so that the effect of reaction time and coal rank upon reactivity can be more easily appraised at each level of severity.

Figure 10 shows the baseline coal conversion for each combination of low and high severity reaction conditions. For the low severity baseline conversions, the $5 \mathrm{~min}$ reaction time resulted in a negative coal conversion for both Wyodak and Illinois \#6 coals. These negative conversions may be attributed to adduction of the co-processing solvent into the primary liquefaction products, forming high molecular weight coal/solvent adducts that are insoluble in THF. This results in a mass gain for the THF insoluble products. As the reaction time is increased to $30 \mathrm{~min}$, negative coal conversions are no longer observed. The low rank coal shows a baseline conversion of 15.0 wt. $\%$ while the high rank coal shows a baseline conversion of $28.7 \mathrm{wt}$. $\%$. This trend of increased baseline conversion in the bituminous coal over the subbituminous coal has been observed in numerous liquefaction studies.

At high severity co-processing conditions $\left(425^{\circ} \mathrm{C}\right)$, solvent incorporation does not appear to be a significant 


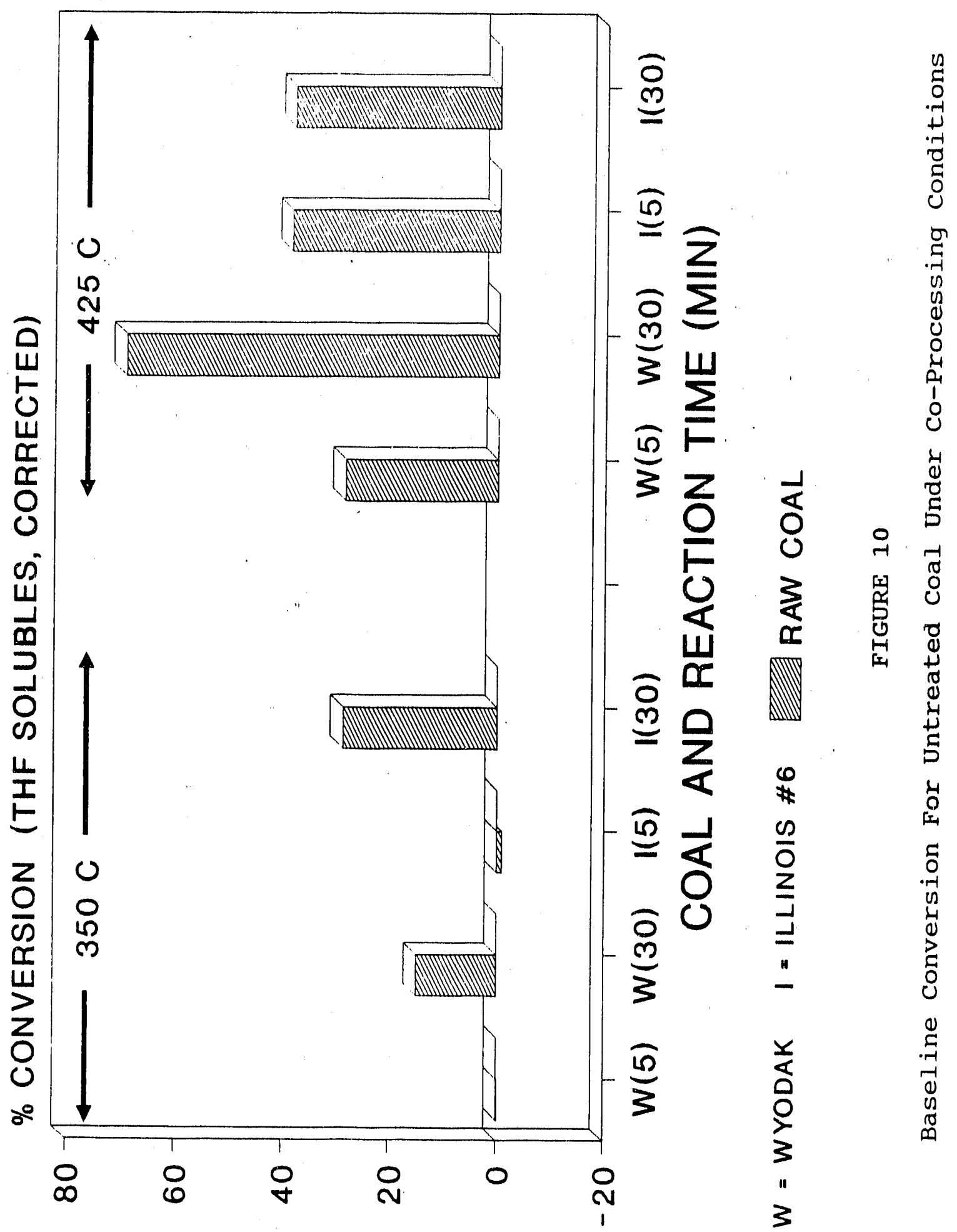


factor. The baseline conversion for untreated wyodak coal is 28.4 wt. \% for a reaction time of $5 \mathrm{~min}$, and 69.3 wt. \% for a reaction time of $30 \mathrm{~min}$. This indicates that for low rank coals, reactivity is still significant at longer reaction times, where the conversion increases as a function of time. The baseline conversions for untreated Illinois \#6 coal are identical within experimental error for both the 5 and $30 \mathrm{~min}$ reaction times $(38.5$ wt. $\%, 38.0$ wt. \%). Although no evidence exists, speculation suggests that coal reactivity at longer reaction times for the high rank coal may be offset by solvent-coal reactions which could be promoted by the higher severity co-processing conditions. The result is that increases in coal conversion due to the higher severity and longer reaction time may be offset by solvent-coal adduction reactions which become more pronounced at longer reaction times, adding mass to the THF insoluble portion of the reaction products.

\subsection{Oxygen Alkylation Co-Processing Experiments}

Co-processing conversion data for coal pretreated using Liotta's oxygen alkylation method are shown in Figure 11 for each combination of reaction conditions. The percent increase in conversion with respect to the baseline conversion for each combination is shown in Figure 12. At low 


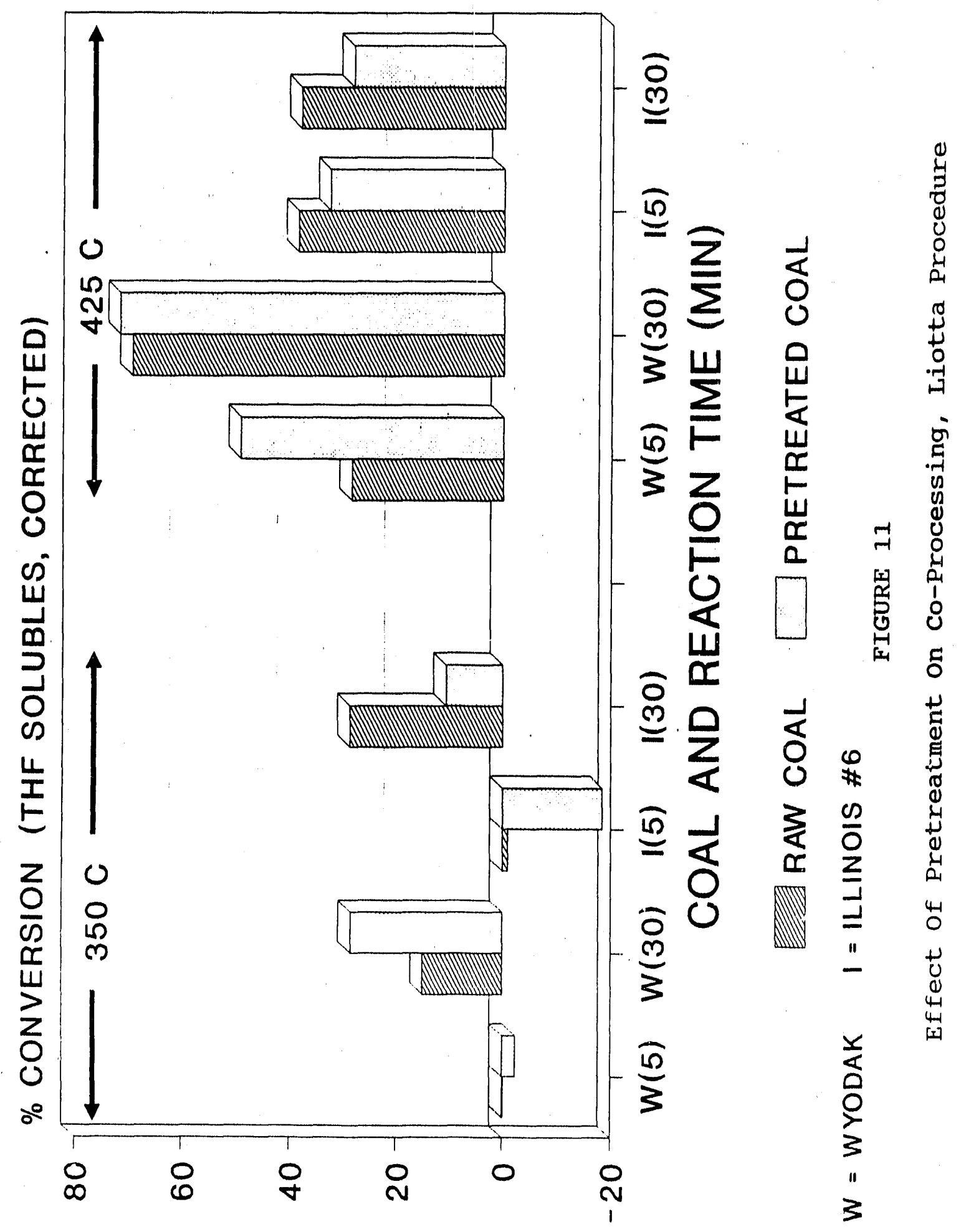




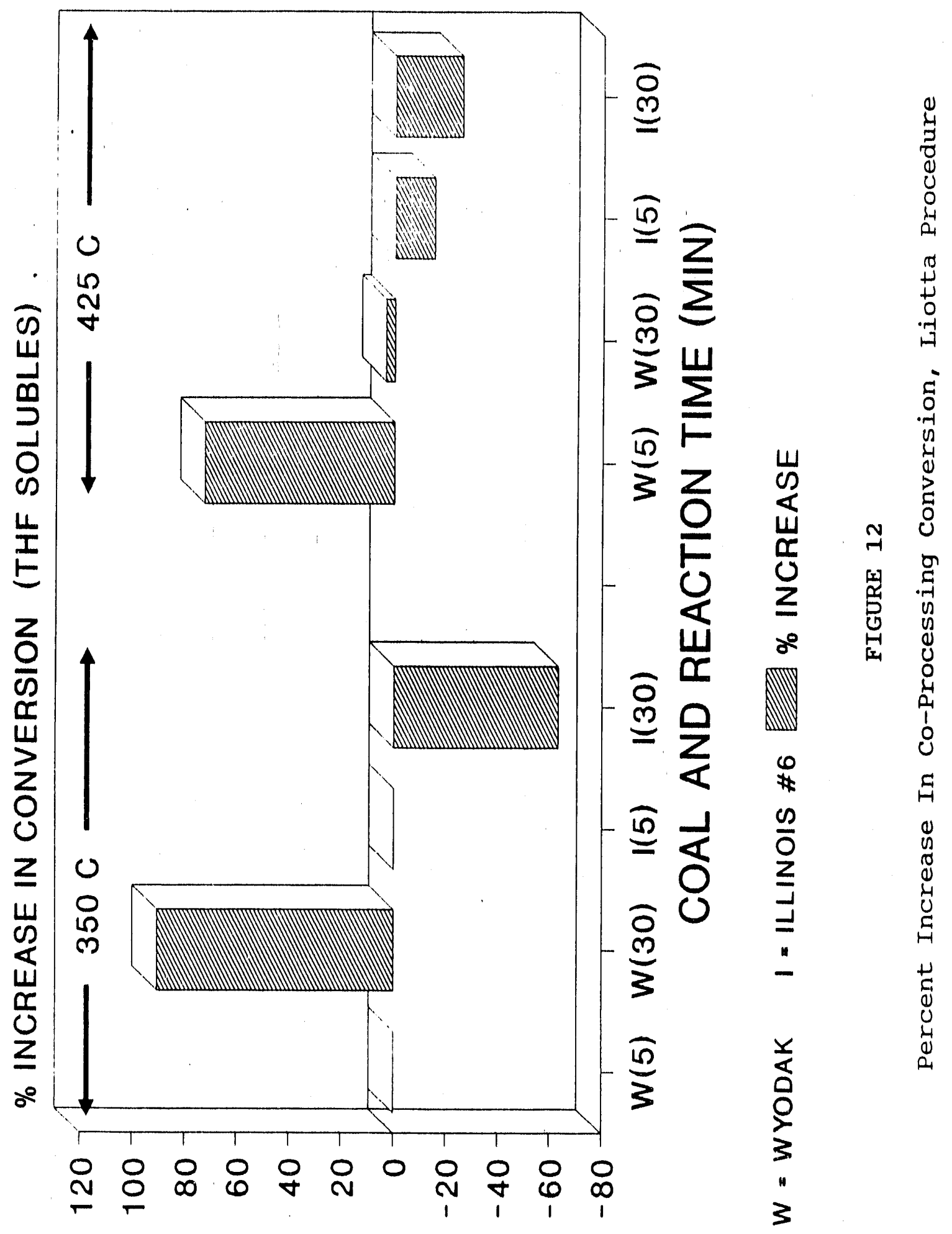


severity co-processing conditions $\left(350^{\circ} \mathrm{C}\right)$ solvent incorporation is significant for both coals at the 5 min reaction time. Coal pretreatment enhances the solvent incorporation effect, further decreasing coal conversion for both Wyodak and Illinois \#6 coals. At $30 \mathrm{~min}$ reaction time, Wyodak coal exhibits a large conversion inorease indicating that pretreatment does result in a significant coal reactivity enhancement. Co-processing of Illinois \#6 coal at the 30 min reaction time resulted in a $63.3 \%$ decrease in conversion, suggesting that pretreatment enhances the solvent incorporation tendency of the system at longer reaction times.

High severity co-processing $\left(425{ }^{\circ} \mathrm{C}\right)$ of Wyodak coal resulted in a significant increase in reactivity enhancement at a reaction time of $5 \mathrm{~min}$, but negligible reactivity enhancement at $30 \mathrm{~min}$. This suggests that, at shorter reaction times, coal pretreatment is beneficial to coal conversion, but at longer reaction times the high severity conditions are sufficient to maximize coal conversion, without the aid of the pretreatment. For both 5 and 30 min reaction times, Illinois \#6 coal showed a percent decrease in conversion. This indicates that pretreatment of Illinois \#6 coal is counterproductive at high severity where retrogressive reactions may be enhanced by the pretreatment process. 


\subsection{Reductive Alkylation Co-Processing Experiments}

Coal conversion data for coal pretreated via sternberg's reductive alkylation process are shown in Figure 13. Baseline conversion for co-processing of untreated coal is also inoluded in this Figure at each combination of reaction conditions. The percent increase in conversion with respect to the untreated coal at each combination of reaction conditions is shown in Figure 14. At low severity, reaction conditions $\left(350{ }^{\circ} \mathrm{C}\right)$, alkylation of wyodak coal results in an increase in reactivity enhancement at reaction times of both 5 and 30 min (Figure 13). Alkylation of Illinois \#6 coal results in a similar increase in reactivity enhancement for both reaction times. Although the Illinois \#6 coal achieves a higher ultimate conversion of 40.4 wt. $\%$, wyodak coal has a lower baseline coal conversion, resulting in a $118.9 \%$ increase in conversion while Illinois \#6 coal showed only a $40.8 \%$ increase in coal conversion (Figure 14).

High severity co-processing $\left(425{ }^{\circ} \mathrm{C}\right)$ of wyodak coal resulted in a significant increase in reactivity enhancement at 5 min reaction time, but a slight decrease in reactivity enhancement at $30 \mathrm{~min}$ reaction time. Once again, the pretreatment process is most beneficial in situations where the baseline coal conversion is low. For 5 and $30 \mathrm{~min}$ coprocessing experiments using Illinols \#6 coal, increases in 


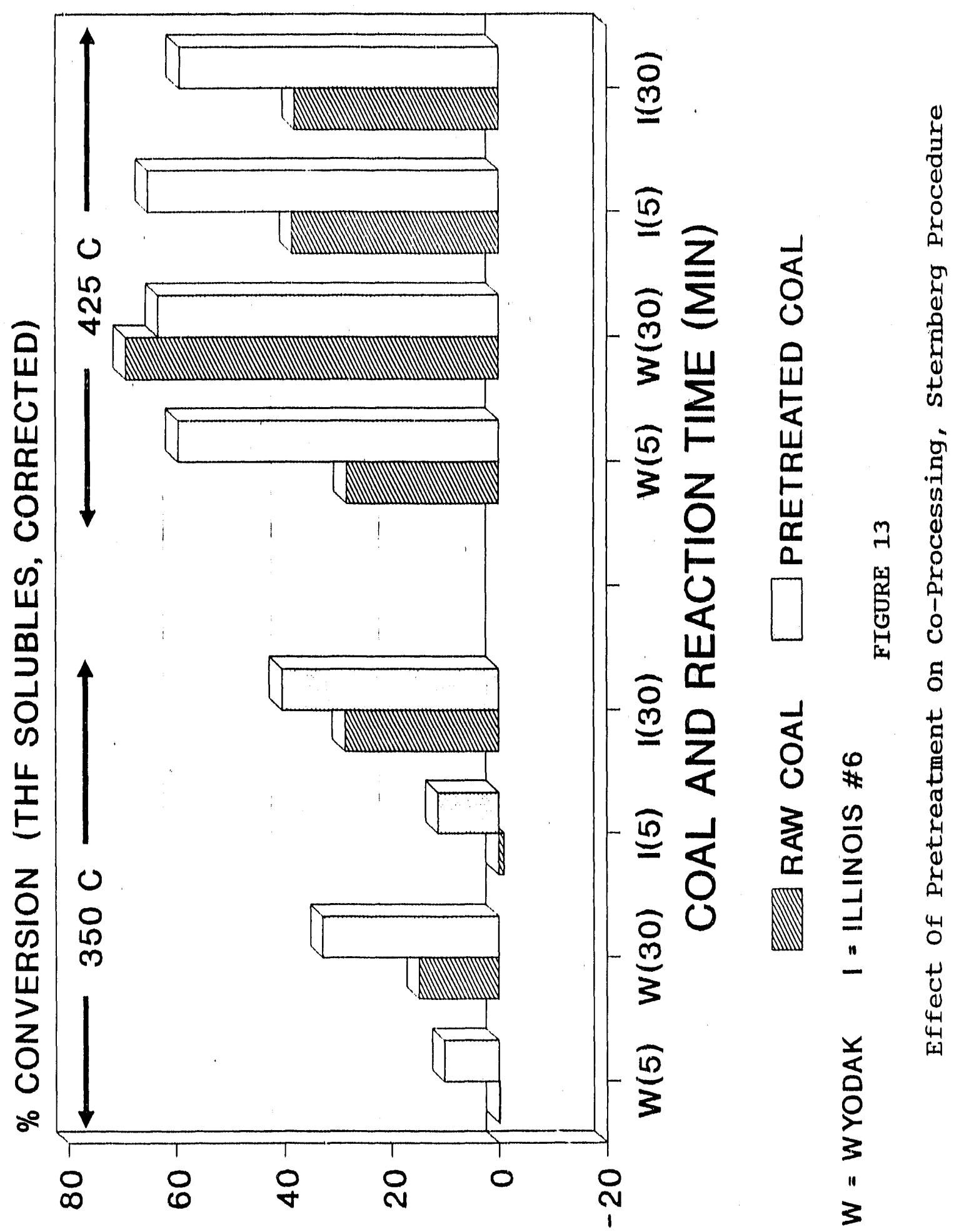




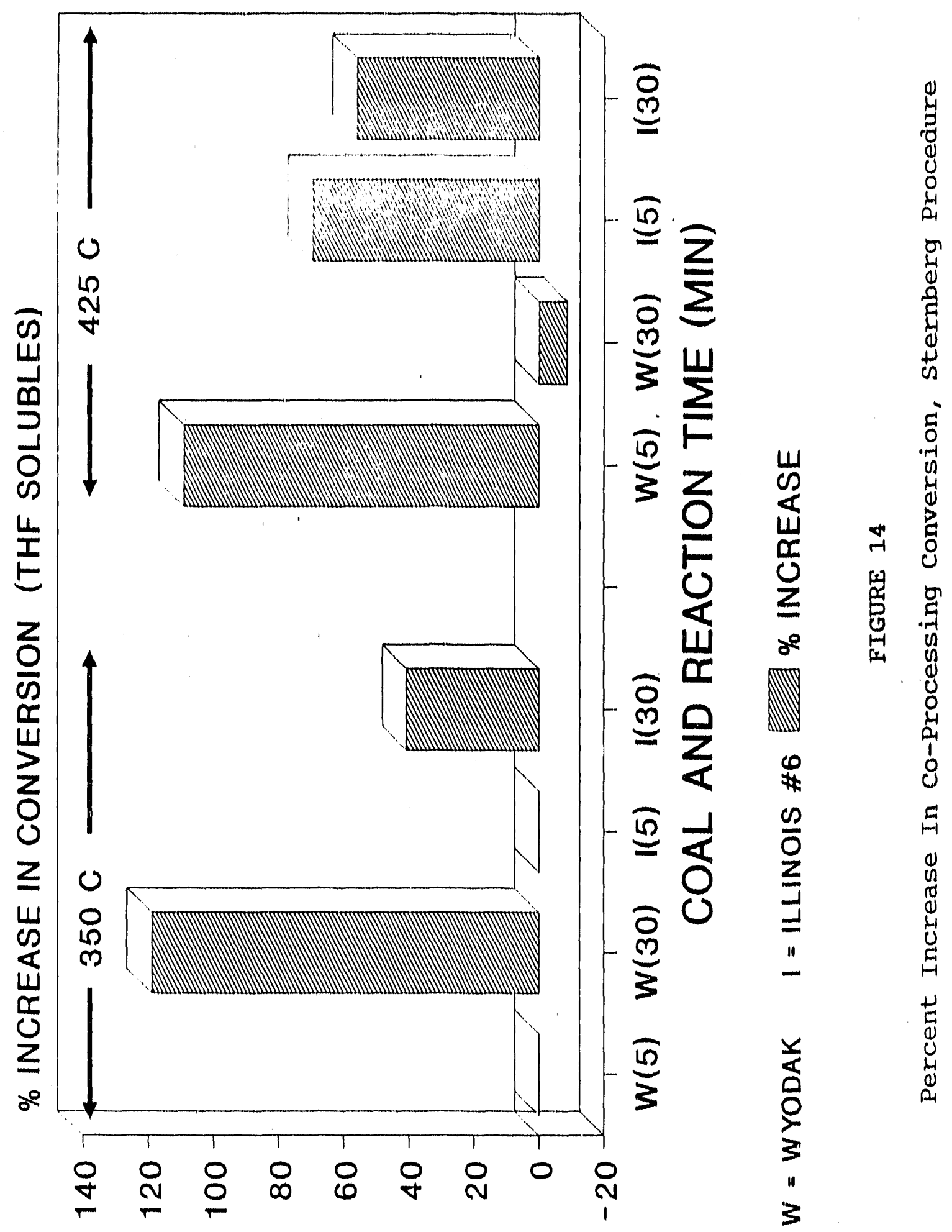


conversion of $69.5 \%$ and $56.1 \%$ were observed. This Indicates that for these particular co-processing conditions, reductive alkylation results in a signiflant increase in reactivity enhancement as reflected in the increase in doal conversion to THF solubles.

6.3 Chlortne Catalyst/Mild Alkylation Co-processing Experiments

Co-processing reactivity experiments using coal samples pretreated with the ohlorine catalyst/mild alkylation pretreatment developed by Armstrong (4) are shown In Figure 15. Baseline conversion of untreated coal at each combination of reaction conditions are also shown for comparison. The percent increase in treated coal conversion with respect to the baseline conversion for each comblnation of reacticir conditions is shown in Figure 16. At low severity coprocessing conditions $\left(350{ }^{\circ} \mathrm{C}\right)$ Wyodak coall shows a modest increase in conversion at both 5 and $30 \mathrm{~min}$ reaction times. Ililnois \#6 coal a.lso showed modest increases in conversion at 5 and $30 \mathrm{~min}$ reaction times, In Figure 16, the percent increase in conversion for Wyodak at $30 \mathrm{~min}$ is higher that the value for Illinois \#6 at $30 \mathrm{~min}$ because Wyodak has a lower baseline coal conversion. Percent increases for the 5 min reaction times were omitted in Figure 16 because of 


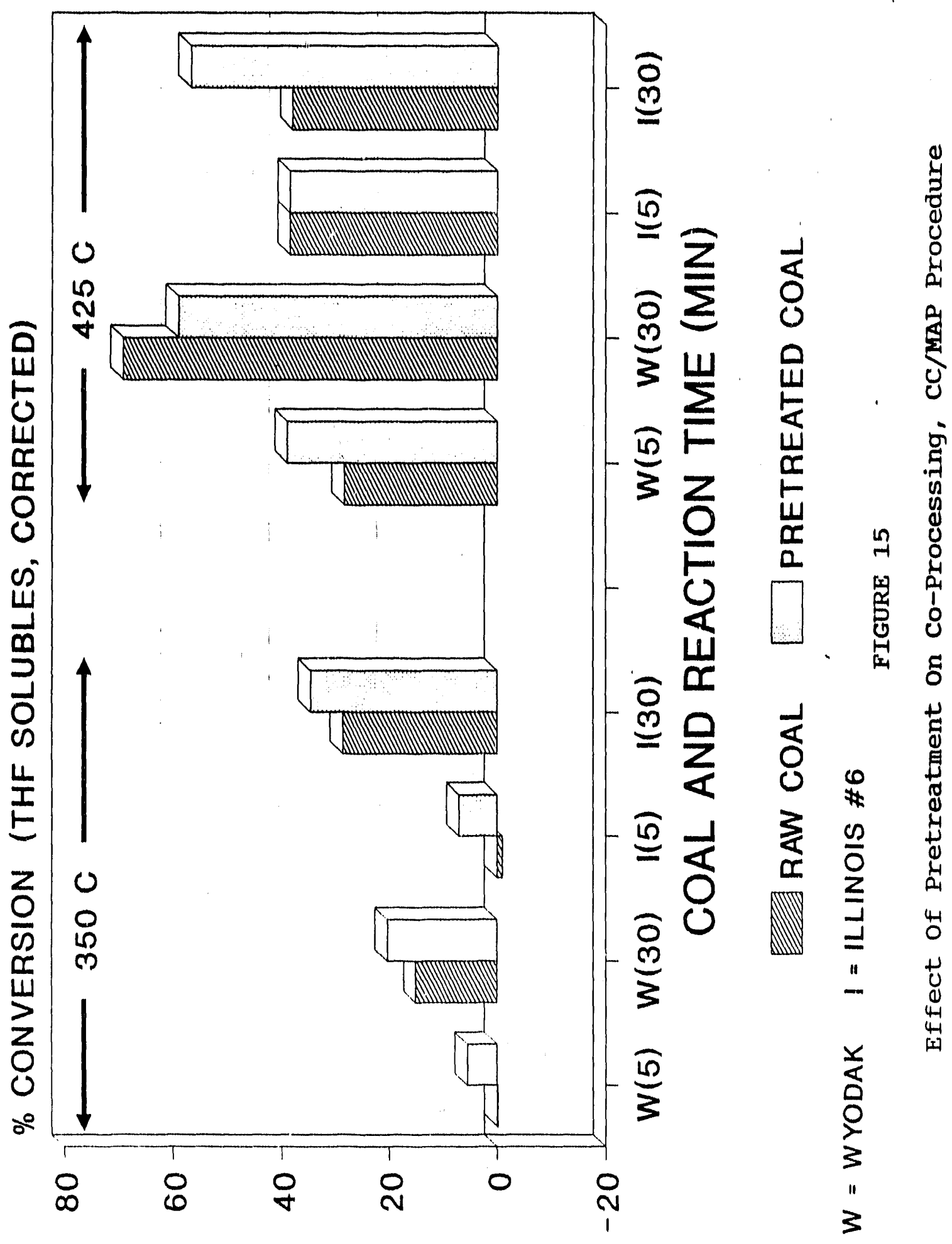




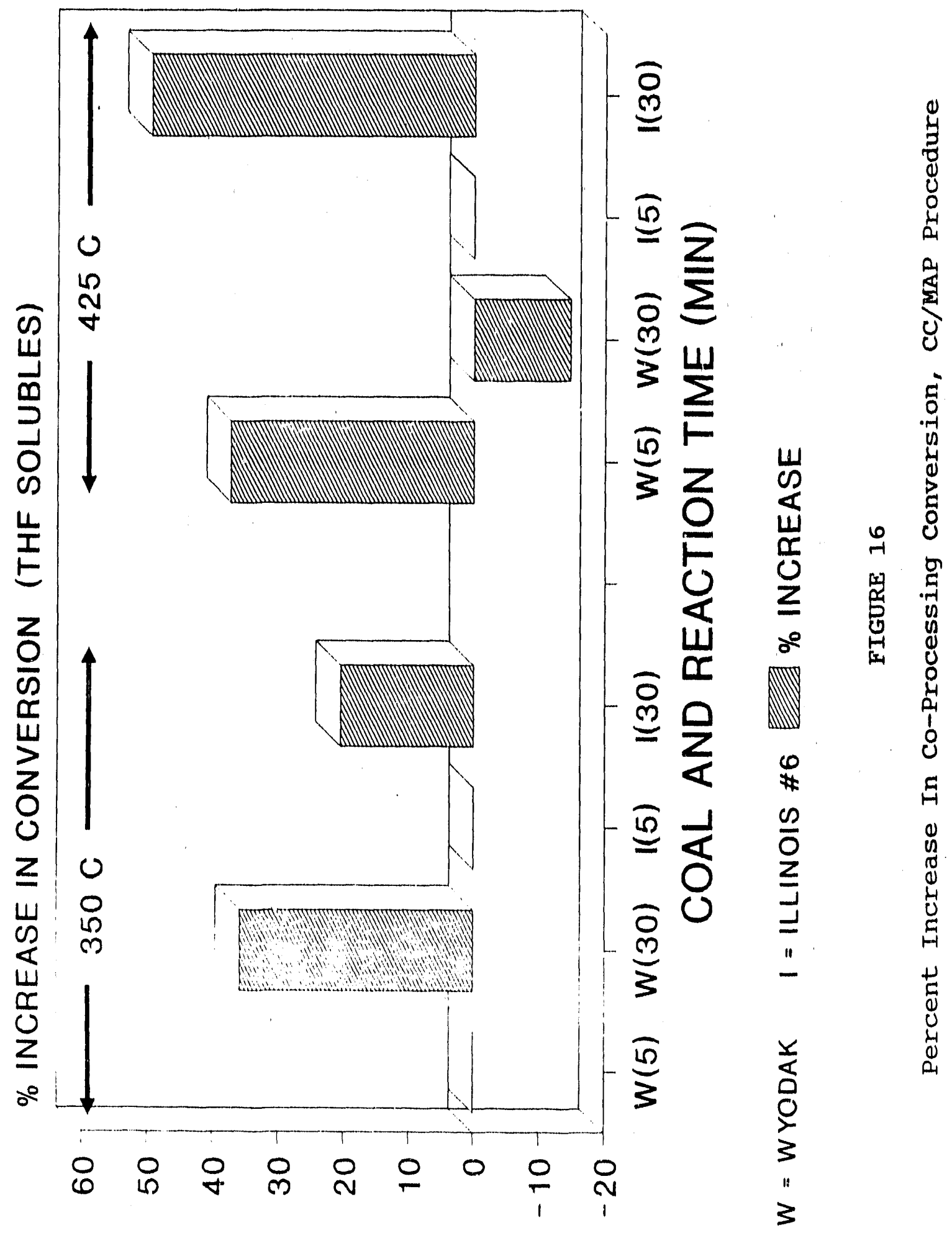


solvent incorporation in baseline conversions.

At high severity co-processing conditions $\left(425{ }^{\circ} \mathrm{C}\right)$ Wyodak coal showed a $37.2 \%$ increase in conversion at a reaction time of $5 \mathrm{~min}$, but a $14.7 \%$ decrease in conversion at $3.0 \mathrm{~min}$ reaction time. Pretreatment at the shorter reaction time enhances coal reactivity but at longer reaction times, the small amount of alkylation which occurs during pretreatment may promote retrogressive coal-solvent interactions. At the 5 min reaction time, pretreatment of Illinois \#6 coal shows no enhancement in coal reactivity, while at $30 \mathrm{~min}$ reaction time a $49.4 \%$ increase in conversion is observed. This may be due to a lesser tendency for the high rank coal to undergo retrogressive reactions after pretreatment.

\section{OPTIMIZATION OF LIQUEFACTION CONDITIONS}

High severity conditions are normally utilized in coal liquefaction processes because baseline coal conversion increases with increasing temperature. Low severity liquefaction conditions, coupled with pretreatment for reactivity enhancement, can be beneficial for coal liquefaction processes. This is because the most significant increase in reactivity enhancement due to coal pretreatment occurs at low temperature, as shown in this thesis. This effect however, decreases with increasing temperature. These two 
opposing trends were observed for all combinations of pretreatment, coal rank, and reaction time, as shown in Figure 17 for Liotta pretreated coal liquefied for $30 \mathrm{~min}$.

Because low temperature favors reactivity enhancement while high temperature favors high ultimate conversion, the most economically effective enhancement in reactivity will occur at some intermediate temperature, where both effects are significant. The determination of this optimal temperature could be made by measuring conversion data at a number of temperature levels between the two extremes utilized in this study. A diagram such as that shown in Figure 18 could then be constructed for each coal and pretreatment combination in order to locate the optimum temperature. Repeated liquefaction experiments where coal, pretreatment method, and reaction time are held constant while reaction temperature is varied would provide the data necessary to construct such a diagram. In the diagram, the intersection of the two curves represents the optimal temperature where the baseline coal conversion is maximized while the percent increase in conversion due to coal pretreatment is still significant for this combination of reactivity parameters. Optimization of the temperature in this manner results in maximization of the reactivity enhancement of the pretreatment process while still maintaining the first stage coal dissolution tempera- 


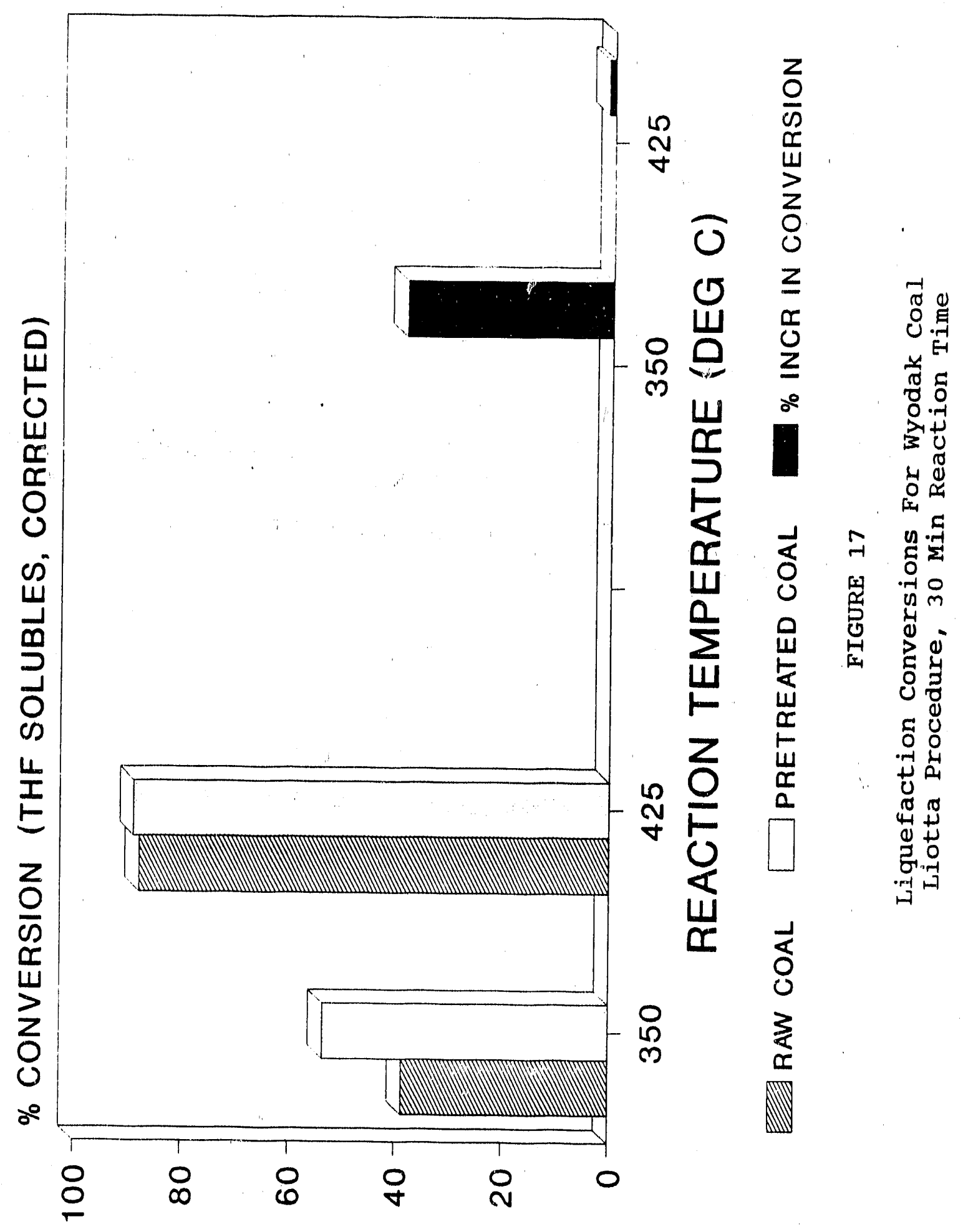




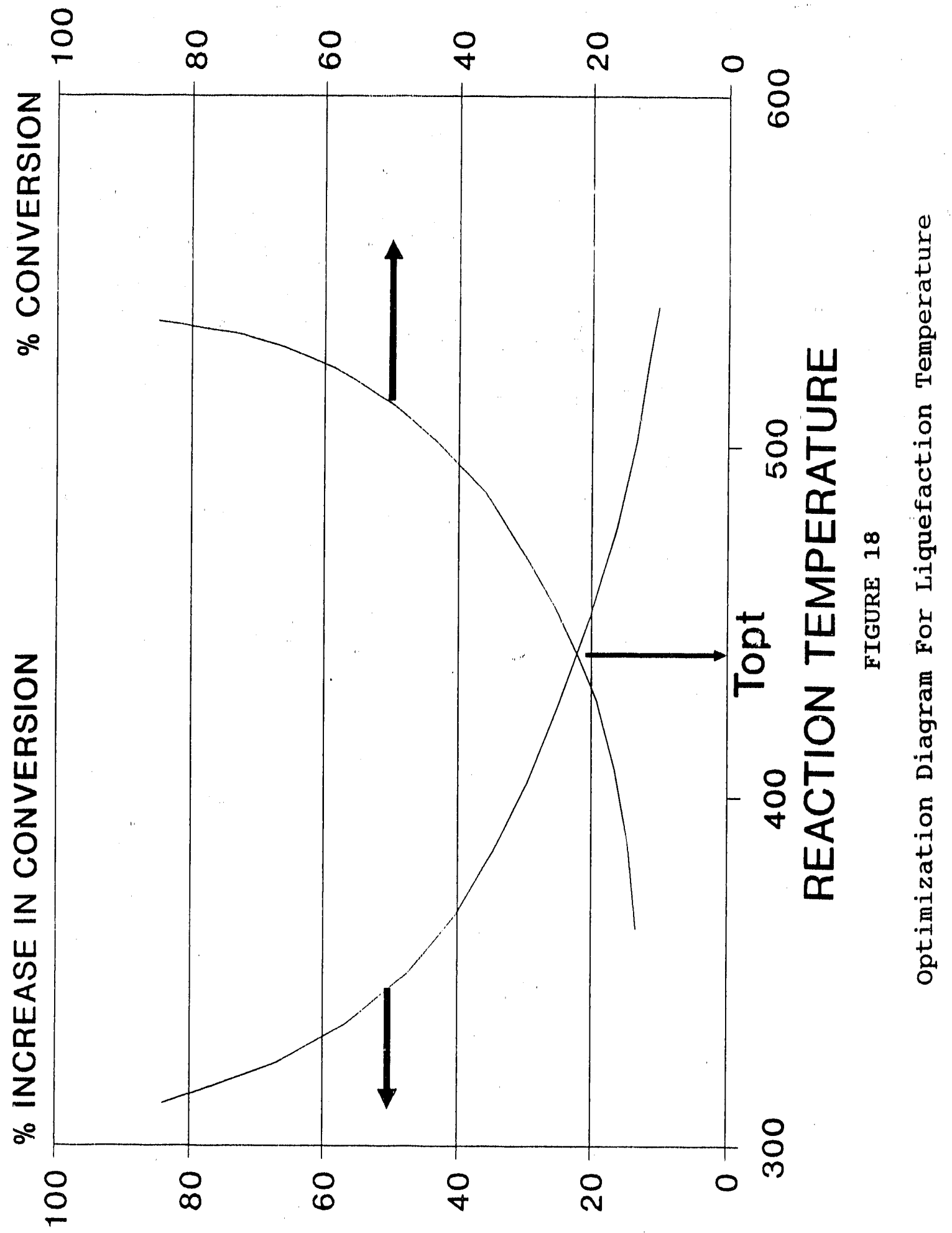


ture at a sufficiently low value to avoid regressive reactions and excessive hydrocarbon gas make. 


\section{CONCLUSIONS}

The objective of this research program was to investigate the effect of selective pretreatment methods upon coal reactivity at different liquefaction and co-processing conditions. The conclusions which can be drawn from this thesis are:

1. The chlorine catalyst/mild alkylation pretreatment method developed by Armstrong slightly alkylates the coal and incorporates a small, but significant amount of chlorine into the coal structure. Reactivity enhancement seen for this pretreatment method is a combination of the effect of alkylation with catalysis caused by the added chlorine.

2. Wyodak coal shows the greatest increase in reactivity enhancement as measured by conversion to THF soluble products under liquefaction conditions for all reaction times, reaction temperatures, and pretreatment methods.

3. The effect of coal pretreatment on reactivity is less significant at high severity $\left(425^{\circ} \mathrm{C}\right)$ liquefaction conditions, where high ultimate coal conversions are observed prior to any pretreatment. Baseline coal conversion to THF 
solubles increases with increasing temperature, but the enhancement in reactivity due to pretreatment decreases with increasing temperature. Determination of an optimum reactivity temperature between the two temperature extremes could result in a maximization of reactivity enhancement for the pretreatment process while still maintaining a significant baseline coal conversion.

4. Co-processing of coal in cold Lake atmospheric residuum at low severity and short reaction times ( $5 \mathrm{~min}$ ) results in significant coal-oil adduct formation which prevents the effects of coal pretreatment upon reactivity from being observed.

5. Low severity co-processing of wyodak coal shows a greater increase in THF coal conversion than Illinois \#6 coal for all pretreatment methods at the $30 \mathrm{~min}$ reaction time.

6. Reductive alkylation results in the greatest percent increase in reactivity enhancement for both high and low rank coals which are co-processed for $30 \mathrm{~min}$ at low severity conditions. 
7. For all pretreatment methods, high severity coprocessing of Wyodak coal results in a significant enhancement in THF conversion at a reaction time of $5 \mathrm{~min}$, but no significant enhancement at a reaction time of $30 \mathrm{~min}$.

8. Reductive alkylation was the only pretreatment which showed a significant increase in the high severity coprocessing reactivity of Illinois \#6 coal at both 5 and 30 min reaction times. 
RECOMMENDATIONS

Based upon the work that has been completed in this thesis, the following areas of liquefaction/co-processing work are recommended for further study:

1. More detailed investigation of coal pretreated with the chlorine catalyst/mild alkylation procedure should be undertaken to determine the relative importance of alkylation and chlorine deposition upon reactivity enhancement.

2. Additional co-processing solvents should be selected for use in reactivity experiments so that potential solvent-pretreatment interactions can be studied.

3. Second stage reactivity experiments under co-processing conditions would indicate the degree to which coal pretreatment enhances the yield of distillable material in two stage processes.

4. Liquefaction experiments at intermediate temperatures would determine the optimal reaction severity in a coalpretreatment system that shows significant reactivity enhancements. 
REFERENCES CITED

1) Vorres, K.S., "Users Handbook for The Argonne Premtum Coal Sample Program", p 11, (1989).

2) The sternberg method is given in varlous references, for example: Sternberg, H.W. and Del Donne, C.L., "Solubilization of Coals by Reductive Alkylation", Fuel, 53, pp 172-175, (1974); or sternberg, H.W., Delle Donne, C.L., Pantages, P., Moronl, E.C. and Markby, R.E., "Solublizzation of an lvb" Coal by Reductive Alkylation", Fuei, 50, pp 432-437, (1971).

3) The Liotta method for selective o-alkylation and prior references to its application in activation of coals may be found in the following journal articles: Liotta, R., "Selective Alkylation of Aaldic Hydroxyl Groups in Coal", Fuel, 58, pp 724-728, (1979); and Schlosberg, Richard H., Neavel, Rlchard C., Maa, Peter S. and Gorbarty, Martin L., "Alkylation: A Beneficial Pretreatment for Coal Liquefaction", Fuel, 59, pp 45-47, (1980).

4) Armstrong, M.E., "Enhancement of Coal Liquefaction Reactivity by Mild Alkylation Pretreatment", Master's Thesis, Colorado School of Mines, Golden, (1988).

5) McMillen, D.F., Malholtra, R., Nigenda, S.E., Min, T.C. and Ross, D.S., "Differing Reactivity of Oxygenated ModelCoal Structures in Hydrogen-Donor and $\mathrm{COH}_{2} \mathrm{O}$ System", Proceedings: 11th Annual EPRI contractors' Conference on clean Liquid and Solid Fuels, pp 5-75 to 5-82, (1987). 
APPENDIX A 
TABLE $A-1$

Reaction Conditions Reference For Untreated Coals

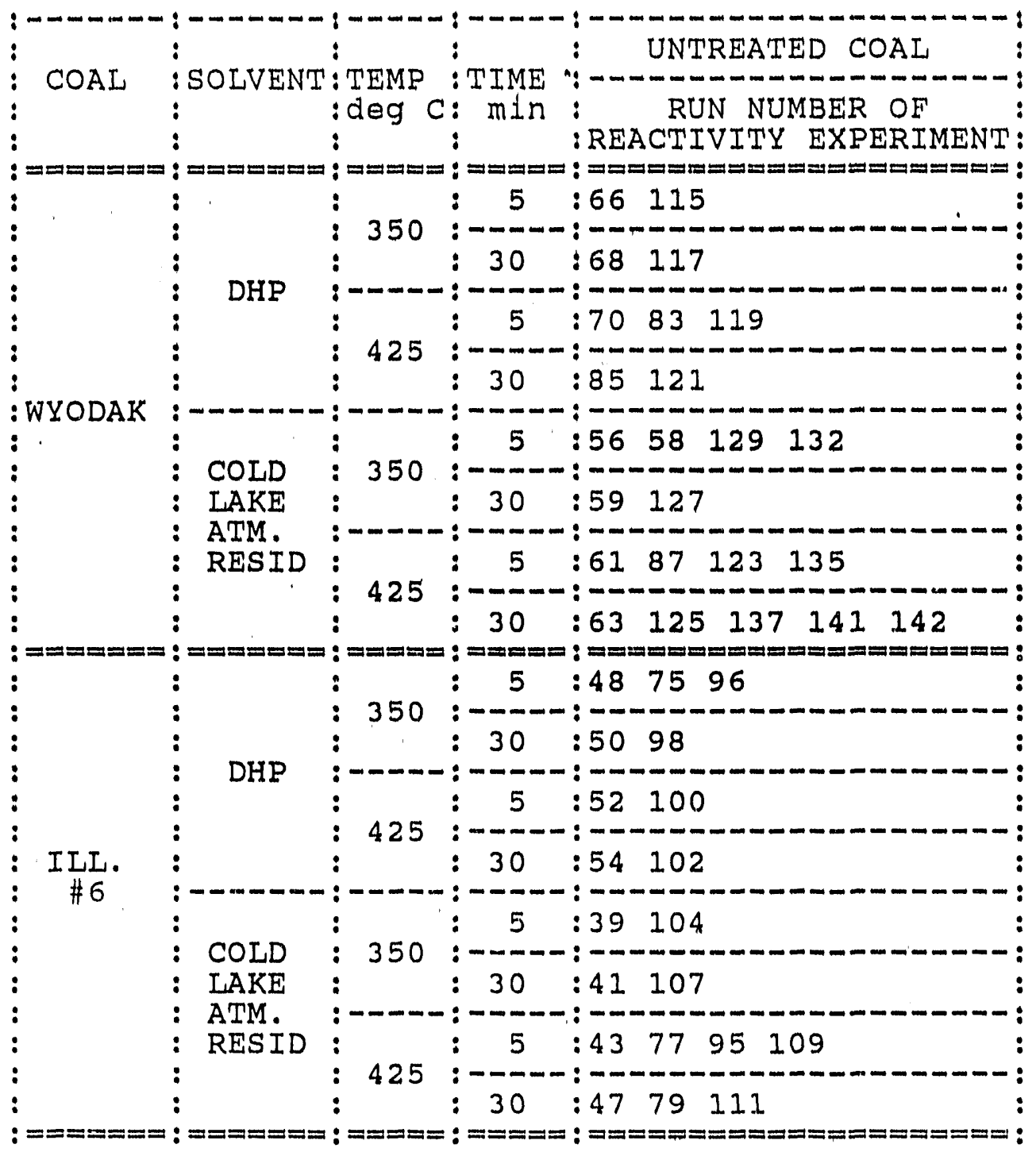


TABLE A-2

Reactivity Runs For Untreated Wyodak Coal

\begin{tabular}{|c|c|c|c|c|c|c|c|c|c|c|}
\hline \multicolumn{7}{|c|}{ WYODAK COAL } & \multicolumn{4}{|l|}{ FRACTION } \\
\hline & & & & & & & INTRINSIC & ADJUSTED & ADJUSTED & \\
\hline & MF COAL & FRACTION & GRAMS ASH & MAF COAL & MF THF & MAF THF & THF INSOLS & MAF COAL & THF COAL & MEAN \\
\hline RUN & IN & ASH IN & IN & IN & INSOL OUT & INSOL OUT & IN FEED & IN & CONV. & CONV. \\
\hline$\#$ & $(g)$ & & $(g)$ & $(g)$ & $(g)$ & $(g)$ & COAL & $(g)$ & $(\%)$ & $(\%)$ \\
\hline$\cdots$ & $\cdots \cdots$ & $\ldots \ldots$ & $\cdots \cdots$ & $\cdots \cdots$ & $\ldots \ldots$ & $\cdots \cdots$ & $\cdots \cdots$ & $\cdots \ldots$ & $\ldots \ldots$ & $\ldots \ldots$ \\
\hline 66 & 0.9956 & 0.0877 & 0.0873 & 0.9083 & 0.8600 & 0.7727 & 0.9837 & 0.8935 & 13.5 & 14.6 \\
\hline 115 & 0.9483 & 0.0877 & 0.0832 & 0.8651 & 0.8000 & 0.7168 & 0.9837 & 0.8510 & 15.8 & \\
\hline 68 & 0.9858 & 0.0877 & 0.0865 & 0.8993 & 0.6200 & 0.5335 & 0.9837 & 0.8847 & 39.7 & 38.7 \\
\hline 117 & 0.9579 & 0.0877 & 0.08840 & 0.8739 & 0.6200 & 0.5360 & 0.9837 & 0.8596 & 37.6 & \\
\hline 70 & 0.4831 & 0.0877 & 0.0424 & 0.4407 & 0.2000 & 0.1576 & 0,9837 & 0.4335 & 63.6 & 65.4 \\
\hline 83 & 0.9495 & 0.0877 & 0.0833 & 0.8662 & 0.3700 & 0.2867 & 0.9837 & 0.8521 & 66.4 & \\
\hline 119 & 0.9483 & 0.0877 & 0.0832 & 0.8651 & 0.3700 & 0.2868 & 0.9837 & 0.8510 & 66.3 & \\
\hline 85 & 0.9788 & 0.0877 & 0.0858 & 0.8930 & 0.1900 & 0.1042 & 0.9837 & 0.8784 & 88.1 & 87.9 \\
\hline 121 & 1.0064 & 0.0877 & 0.0883 & 0.9181 & 0.2000 & 0.1117 & 0.9837 & 0.9032 & 87.6 & \\
\hline 56 & 0.9759 & 0.0877 & 0.0856 & 0.8903 & 0.9600 & 0.8744 & 0.9837 & 0.8758 & 0.2 & .0 .2 \\
\hline 58 & 0.9858 & 0.0877 & 0.0865 & 0.8993 & 0.9600 & 0.8735 & 0.9837 & 0.8847 & 1.3 & \\
\hline 129 & 0.9579 & 0.0877 & 0.0840 & 0.8739 & 0.8900 & 0.8060 & 0.9837 & 0.8596 & 6.2 & \\
\hline 132 & 0.9340 & 0.0877 & 0.0819 & 0.8521 & 0.9900 & 0.9081 & 0.9837 & 0.8382 & -8.3 & \\
\hline 59 & 0.9759 & 0.0877 & 0.0856 & 0.8903 & 0.8300 & 0.7444 & 0.9837 & 0.8758 & 15.0 & 15.0 \\
\hline 127 & 0.9870 & 0.0877 & 0.0866 & 0.9004 & 0.8400 & 0.7534 & 0.9837 & 0.8858 & 14.9 & \\
\hline 61 & 0.9858 & 0.0877 & 0.0865 & 0.8993 & 0.7200 & 0.6335 & 0.9837 & 0.8847 & 28.4 & 28.4 \\
\hline 87 & 0.9396 & 0.0877 & 0.0824 & 0.8572 & 0.6700 & 0.5876 & 0.9837 & 0.8432 & 30.3 & \\
\hline $123 *$ & 0.9773 & 0.0877 & 0.0857 & 0.8916 & 0.6500 & 0.5643 & 0.9837 & 0.8771 & 35.7 & \\
\hline 135 & 0.9247 & 0.0877 & 0.0811 & 0.8436 & 0,6900 & 0.6089 & 0.9837 & 0.8299 & 26.6 & \\
\hline 137 & 0.9247 & 0.0877 & 0.0811 & 0.8436 & 0.3700 & 0.2889 & 0.9837 & 0.8299 & 65.2 & 69.3 \\
\hline 141 & 0.7747 & 0.0877 & 0.0679 & 0.7068 & 0.3300 & 0.2621 & 0.9837 & 0.6952 & 62.3 & \\
\hline 142 & 0.9587 & 0,0877 & 0.0841 & 0.8746 & 0.3100 & 0.2259 & 0.9837 & 0.8604 & 73.7 & \\
\hline 125 & 0.9579 & 0.0877 & 0.0840 & 0.8739 & 0.2900 & 0.2060 & 0.9837 & 0.8596 & 76.0 & \\
\hline $63^{*}$ & 0.9660 & 0.0877 & 0.0847 & 0.8813 & 0.4500 & 0.3653 & 0.9837 & 0.8669 & 57.9 & \\
\hline
\end{tabular}

* indicates outlying value not used in calculation of mean conversion 
TABLE $A-3$

Reaotivity Runs For Untreated Ilinois \#6 Coal.

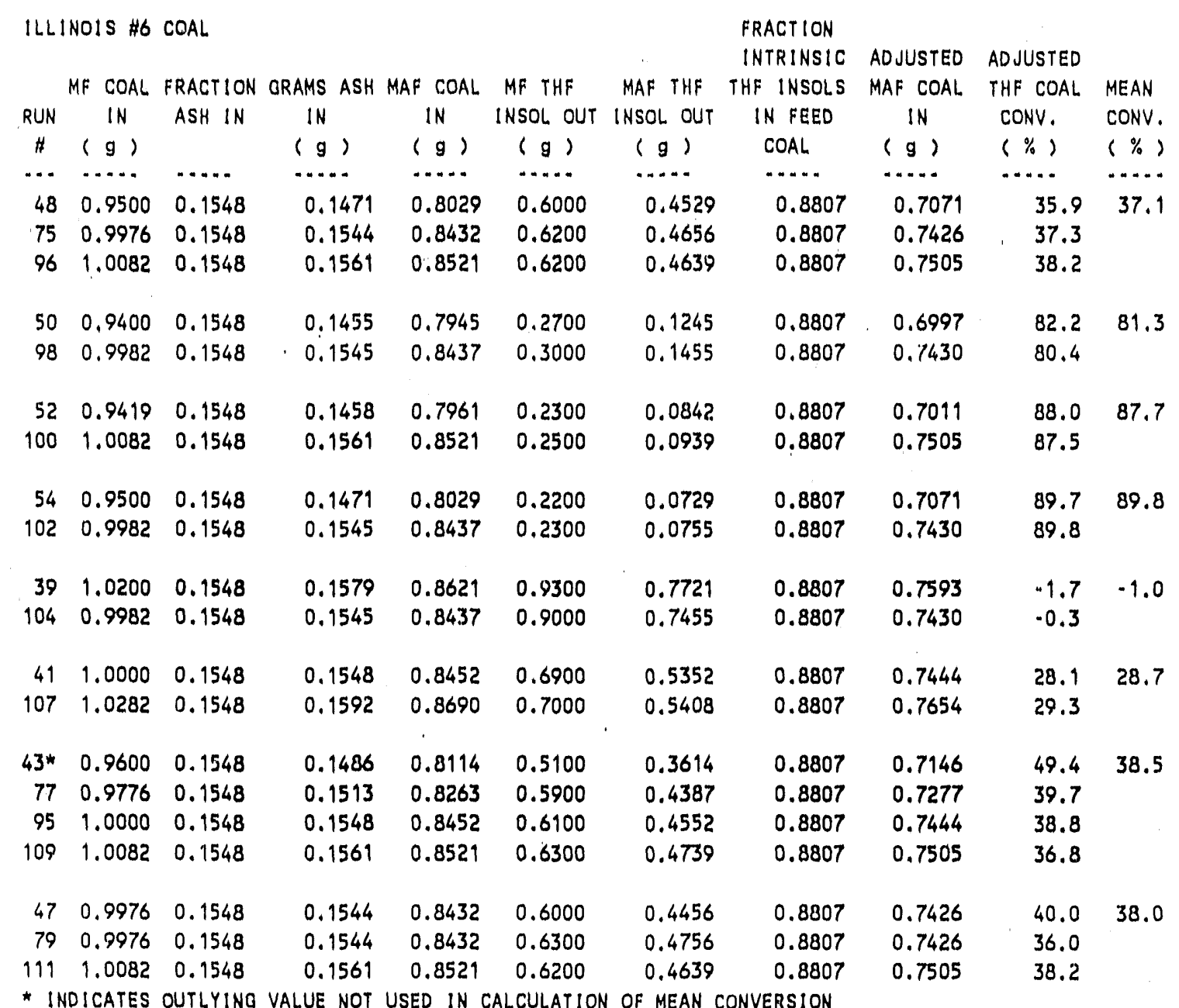


TABLE A-4

Reaction Conditions Reference For Liotta Pretreated Coals

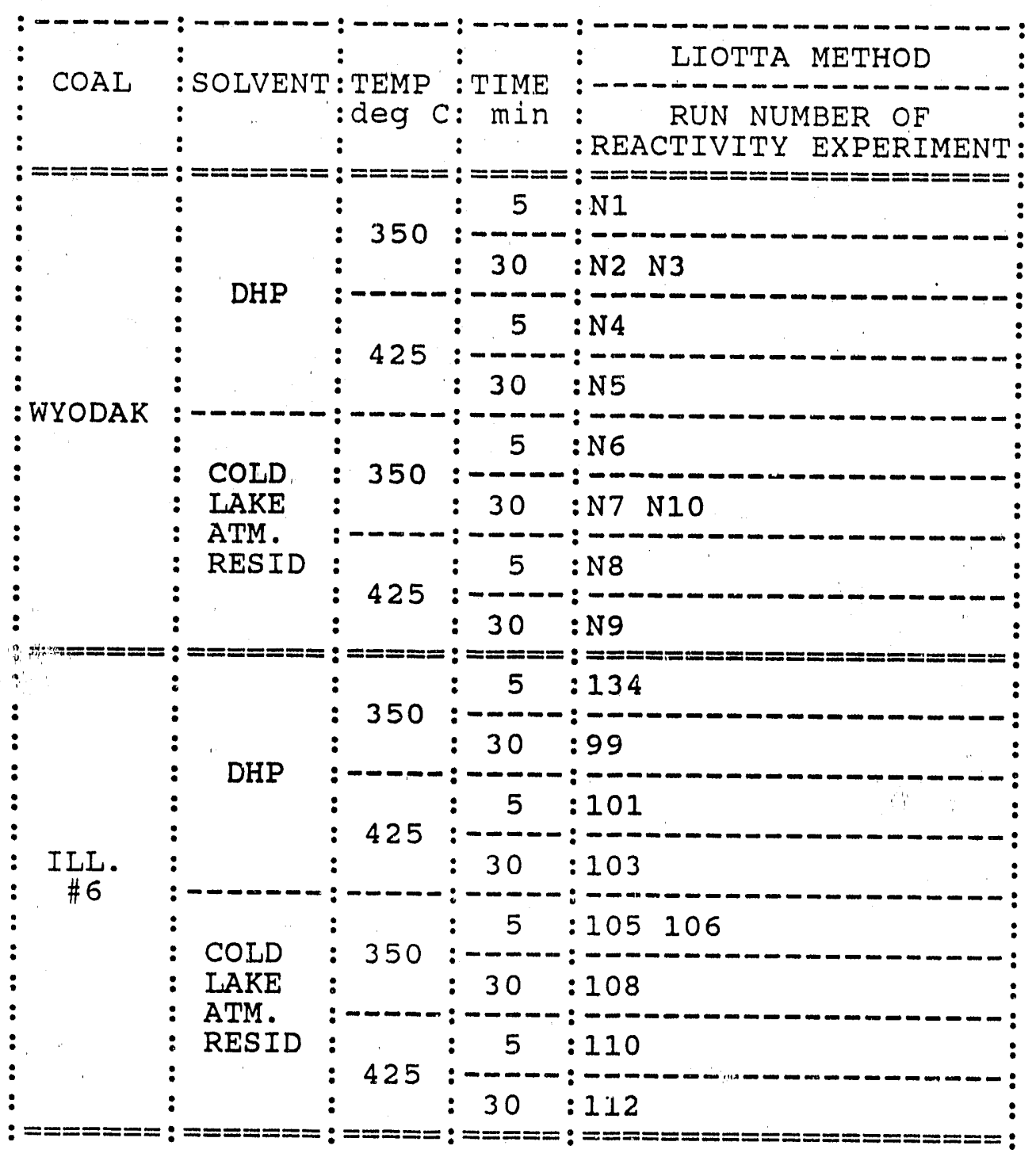


TABLE A-5

Reactivity Runs For Liotta Pretreated Wyodak Coal

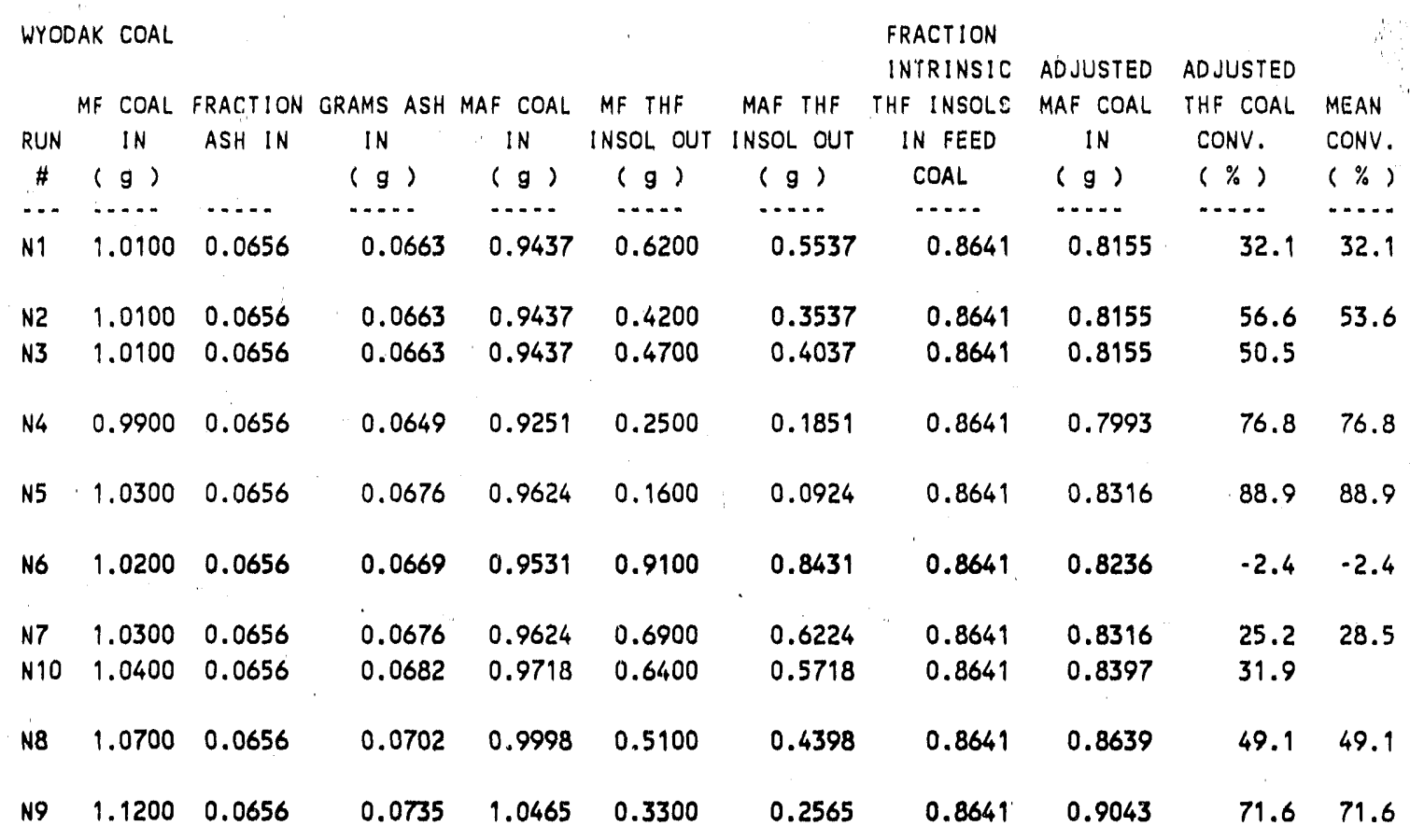


TABLE A-6

Reactivity Runs For Liotta Pretreated Illinois \#6 coal

\begin{tabular}{|c|c|c|c|c|c|c|c|c|c|c|}
\hline \multicolumn{7}{|c|}{ ILL!NOIS \#6 COAL } & \multicolumn{4}{|l|}{ FRACTION } \\
\hline & & & & & & & INTRINSIC & AD JUSTED & ADJUSTED & \\
\hline & MF COAL & FRACTION & GRAMS ASH & MAF COAL & MF THF & MAF THF & THF INSOLS & MAF COAL & THF COAL & MEAN \\
\hline JN & IN & ASH IN & IN & IN & INSOL OUT & INSOL OUT & IN FEED & IN & CONV. & CONV. \\
\hline$H$ & $(g)$ & & $(g)$ & $(g)$ & $(g)$ & $(g)$ & COAL & $(g)$ & $(\%)$ & $(\%)$ \\
\hline$\cdots$ & ..... & ..... & ...... & $\cdots$ & (..... & $\cdots \cdot$ & $\cdots$ & .... & $\ldots$. & $\cdots \cdots$ \\
\hline 134 & 0.9624 & 0.1434 & 0.1380 & 0.8244 & 0.4700 & 0.3320 & 0.7468 & 0.6157 & 46.1 & 46.1 \\
\hline 99 & 0.9922 & 0.1434 & 0.1423 & 0.8499 & 0.2400 & 0.0977 & 0.7468 & 0.6347 & 84.6 & 84.6 \\
\hline 01 & 0.9823 & 0.1434 & 0.1409 & 0.8414 & 0.2100 & 0.0691 & 0.7468 & 0.6284 & 89.0 & 89.0 \\
\hline 103 & 0.9922 & 0.1434 & 0.1423 & 0.8499 & 0.2000 & 0.0577 & 0.7468 & 0.6347 & 90.9 & 90.9 \\
\hline 105 & 0.9823 & 0.1434 & 0.1409 & 0.8414 & 0.8900 & 0.7491 & 0.7468 & 0.6284 & -19.2 & -18.5 \\
\hline 106 & 0.9922 & 0.1434 & 0.1423 & 0.8499 & 0.8900 & 0.7477 & 0.7468 & 0.6347 & -17.8 & \\
\hline 08 & 0.9128 & 0.1434 & .1309 & 0.7819 & 0.6700 & 0.5391 & 0.7468 & 0.5839 & 7.7 & 10.6 \\
\hline N262 & 1.0086 & 0.1434 & 0.1446 & 0.8640 & 0.7300 & 0.5854 & 0.7468 & 0.6452 & 9.3 & \\
\hline N263 & 1.0885 & $0.14,34$ & 0.1561 & 0.9324 & 0.7500 & 0.5939 & 0.7468 & 0.6963 & 14.7 & \\
\hline 110 & 0.9922 & 0.1434 & 0.1423 & 0.8499 & 0.5700 & 0.4277 & 0.7468 & 0.6347 & 32.6 & 32.6 \\
\hline 12 & 1.0616 & 0.1434 & 1.9522 & 0.9094 & 0.6400 & 0.4878 & 0.7468 & 0.6791 & 28.2 & 28.2 \\
\hline
\end{tabular}




\section{TABLE A-7}

Reaction Conditions Reference For Sternberg Pretreated Coals

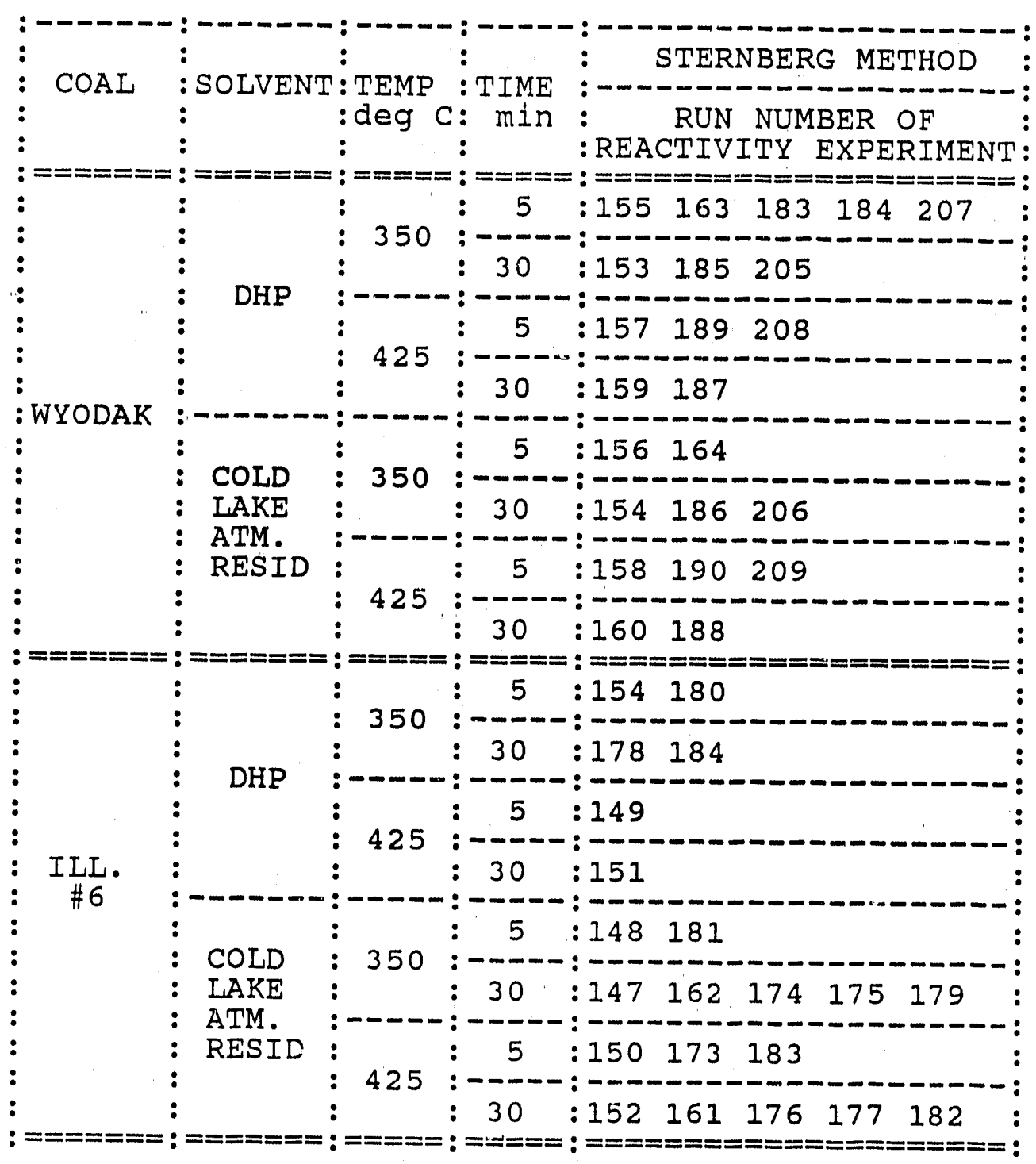


TABLE A-8

\section{Reactivity Runs For sternberg Pretreated Wyodak Coal}

\begin{tabular}{|c|c|c|c|c|c|c|c|c|c|c|}
\hline \multicolumn{6}{|c|}{ WYODAK 0} & \multicolumn{4}{|c|}{ FRACTION } & \\
\hline & & & & & & & INTRINSIC & ADJUSTED & ADJUSTED & \\
\hline & MF COAL & FRACTION & GRAMS ASH & MAF COAL & MF THF & MAF THF & THF INSOLS & MAF COAL & THF COAL & MEAN \\
\hline RUN & IN & ASH IN & IN & IN & INSOL OUT & INSOL OUT & IN FEED & IN & CONV. & CONV. \\
\hline$\#$ & $(g)$ & & $(g)$ & $(g)$ & $(g)$ & $(g)$ & COAL & $(g)$ & $(\%)$ & $(\%)$ \\
\hline$\cdots$ & $\ldots$ & $\ldots$. & $\cdots$ & $\ldots$. & $\ldots$. & $\cdots$ & $\cdots \cdots$ & $\cdots$ & $\cdots$ & $\ldots .$. \\
\hline 155 & 0.9362 & 0.1268 & 0.1187 & 0.8175 & 0.6600 & 0.5413 & 1.0000 & 0.8175 & 33.8 & 30.1 \\
\hline 163 & 0.7899 & 0.1268 & 0.1002 & 0.6897 & 0.6600 & 0.5598 & 1.0000 & 0.6897 & 18.8 & \\
\hline $183^{*}$ & 0.7800 & 0.1268 & 0.0989 & 0.6811 & 0.3300 & 0.2311 & 1.0000 & 0.6811 & 66.1 & \\
\hline 184 & 1.0101 & 0.1268 & 0.1281 & 0.8820 & 0.6200 & 0.4919 & 1.0000 & 0.8820 & 44.2 & \\
\hline 207 & 0.8796 & 0.1268 & 0.1115 & 0.7681. & 0.7000 & 0.5885 & 1.0000 & 0.7681 & 23.4 & \\
\hline $153^{*}$ & 0.8874 & 0.1268 & 0.1125 & 0.7749 & 0.5200 & 0.4075 & 1.0000 & 0.7749 & 47.4 & 64.7 \\
\hline 185 & 0.9906 & 0.1268 & 0.1256 & 0.8650 & 0.4300 & 0.3044 & 1.0000 & 0.8650 & 64.8 & \\
\hline 205 & 0.8015 & 0.1268 & 0.1016 & 0.6999 & 0.3500 & 0.2484 & 1.0000 & 0.6999 & 64.5 & \\
\hline 157 & 0.8777 & 0.1268 & 0.1113 & 0.7664 & 0.3000 & 0.1887 & 1.0000 & 0.7664 & 75.4 & 79.6 \\
\hline 189 & 0.9615 & 0.1268 & 0.1219 & 0.8396 & 0.2600 & 0.1381 & 1.0000 & 0.8396 & 83.6 & \\
\hline 208 & 0.8894 & 0.1268 & 0.1128 & 0.7766 & 0.2700 & 0.1572 & 1.0000 & 0.7766 & 79.8 & \\
\hline 159 & 0.8679 & 0.1268 & 0.1100 & 0.7579 & 0.1800 & 0.0700 & 1.0000 & 0.7579 & 90.8 & 90.0 \\
\hline 187 & 0.9518 & 0.1268 & 0.1207 & 0.8311 & 0.2100 & 0.0893 & 1.0000 & 0.8311 & 89.3 & \\
\hline 156 & 0.8777 & 0.1268 & 0.1113 & 0.7664 & 0.7900 & 0.6787 & 1.0000 & 0.7664 & 11.4 & 10.2 \\
\hline 164 & 0.7704 & 0.1268 & 0.0977 & 0.6727 & 0.7100 & 0.6123 & 1.0000 & 0.6727 & 9.0 & \\
\hline 154 & 0.9069 & 0.1268 & 1150 & 0.7919 & .7200 & 0.6050 & 1.0000 & 0.7919 & 23.6 & 32.8 \\
\hline 186 & 0.9906 & 0.1268 & 0.1256 & 0.8650 & 0.6300 & 0.5044 & 1.0000 & 0.8650 & 41.7 & \\
\hline 206 & 0.8992 & 0.1268 & 0.1140 & 0.7852 & 0.6400 & 0.5260 & 1.0000 & 0.7852 & 33.0 & \\
\hline $158^{*}$ & 0.8972 & 0.1268 & 0.1138 & 0.7834 & 0.5800 & 0.4662 & 1.0000 & 0.7834 & 40.5 & 59.5 \\
\hline 190 & 0.9712 & 0.1268 & 0.1231 & 0.8481 & 0.4700 & 0.3469 & 1.0000 & 0.8481 & 59.1 & \\
\hline 209 & 0.8796 & 0.1268 & 0.1115 & 0.7681 & 0.4200 & 0.3085 & 1.0000 & 0.7681 & 59.8 & \\
\hline 160 & 0.8972 & 0.1268 & 0.1138 & 0.7834 & 0.4100 & 0.2962 & 1.0000 & 0.7834 & 62.2 & 63.3 \\
\hline 188 & 0.9809 & 0.1268 & 0.1244 & 0.8565 & 0.4300 & 0.3056 & 1.0000 & 0.8565 & 64.3 & \\
\hline
\end{tabular}

* indicates outlying value not used in calfulation of mean conversion 
TABLE A-9

Reactivity Runs For Sternberg Pretreated Illinois \#6 Coal

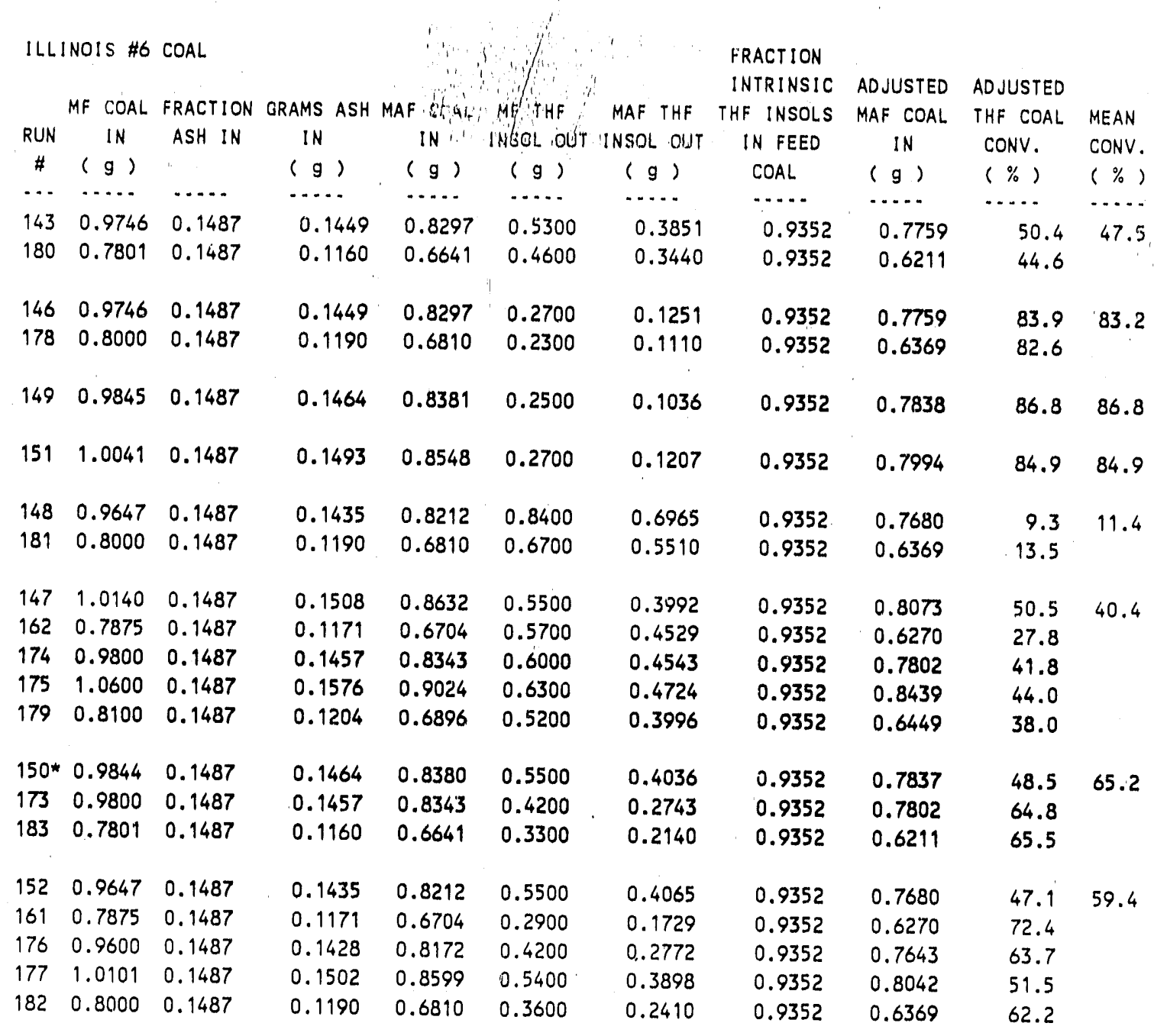

* indicates outlying value not used in calculation of mean conversion 
TABLE A-10

Reaction Conditions Reference For CC/MAP Pretreated Coals

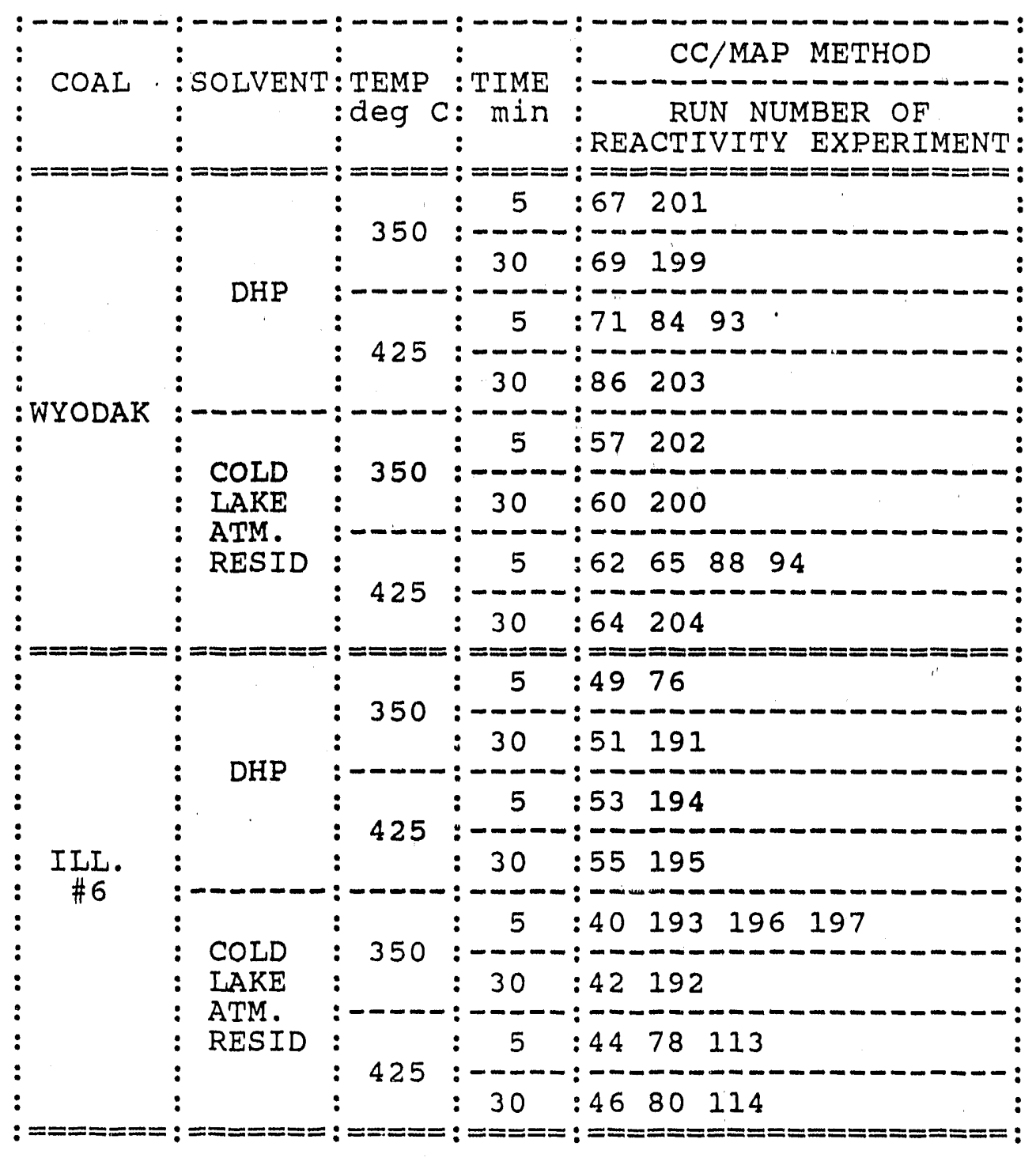


TABLE $A-11$

Reactivity Runs for CC/MAP Pretreated Wyodak Coal

\begin{tabular}{|c|c|c|c|c|c|c|c|c|c|c|}
\hline \multicolumn{7}{|c|}{ WYOOAK COAL. } & \multicolumn{4}{|l|}{ FRACTION } \\
\hline & & & & & & & INTRINSIC & ADJUSTED & AD JUSTED & \\
\hline & MF COAL & FRACTION & GRAMS ASH & MAF COAL & MF THF & MAF THF & THF INSOLS & MAF COAL & THF COAL & MEAN \\
\hline RUN & IN & ASH IN & IN & IN & INSOL OUT & INSOL OUT & IN FEED & IN & CONV. & CONV. \\
\hline$\#$ & $(g)$ & & $(g)$ & $(g)$ & $(9)$ & $(g)$ & COAL & $(g)$ & $(\%)$ & $(\%)$ \\
\hline$\cdots$ & $\cdots$ & $\ldots$. & $\ldots$ & $\cdots$ & $\cdots \cdots$ & $\cdots$ & $\ldots$. & $\cdots \cdot$ & $\cdots \cdots$ & $\ldots$. \\
\hline 67 & 0.9758 & 0.0783 & 0.0764 & 0.8994 & 0.7200 & 0.6436 & 0.9414 & 0.8467 & 24.0 & 25.6 \\
\hline 201 & 0.9719 & 0.0783 & 0.0761 & 0.8958 & 0.6900 & 0.6139 & 0.9414 & 0.8433 & 27.2 & \\
\hline 69 & 0.4784 & 0.0783 & 0.0375 & 0.4409 & 0.2500 & 0.2125 & 0.9414 & 0.4151 & 48.8 & 51.4 \\
\hline 199 & 0.9435 & 0.0783 & 0.0739 & 0.8696 & 0.4500 & 0.3761 & 0.9414 & 0.8187 & 54.1 & \\
\hline & & & & & & & & 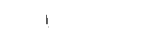 & & \\
\hline 71 & 0.4784 & 0.0783 & 0.0375 & 0.4409 & 0.1500 & 0.1125 & 0.9414 & 0.4151 & 72.9 & 82.6 \\
\hline 84 & 0.9591 & 0.0783 & 0.0751 & 0.8840 & 0.2000 & 0.1249 & 0.9414 & 0.8322 & 85.0 & \\
\hline 93 & 0.7844 & 0.0783 & 0.0614 & 0.7230 & 0.1300 & 0.0686 & 0.9414 & 0.6806 & 89.9 & \\
\hline 86 & 0.8727 & 0.0783 & 0.0683 & 0.8044 & 0.1600 & 0.0917 & 0.9414 & 0.7572 & 87.9 & 89.7 \\
\hline 203 & 0.9816 & 0.0783 & 0.0769 & 0.9047 & 0.1500 & 0.0731 & 0.9414 & 0.8517 & 91.4 & \\
\hline 202 & 0.9341 & 33 & 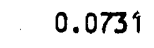 & 10 & 00 & & & 0.8 & 5.4 & 5.4 \\
\hline 57 & 0.9566 & 0.0783 & 0.0749 & 0.8817 & 0.8600 & 0.7851 & 0.9414 & 0.8300 & 5.4 & \\
\hline 60 & 0.9566 & 0.0783 & 0.0749 & 0.8817 & 0.7500 & 0.6751 & 0.9414 & 0.8300 & 18.7 & 20.3 \\
\hline 200 & 0.9531 & 0.0783 & 0.0746 & 0.8785 & 0.7200 & 0.6454 & 0.9414 & 0.8270 & 22.0 & \\
\hline 62 & 0.9566 & 0.0783 & 0.0749 & 0.8817 & 0.4900 & 0.4159 & 0.9414 & 0.8300 & 50.0 & 39.0 \\
\hline 65 & 0.9566 & 0.0783 & 0.0749 & 0.8817 & 0.6700 & 0.5951 & 0.9414 & 0.8300 & 28.3 & \\
\hline 88 & 0.7768 & 0.0783 & 0.0608 & 0.7160 & 0.4800 & 0.4192 & 0.9414 & 0.6740 & 37.8 & \\
\hline 94 & 0.7844 & 0.0783 & 0.0614 & 0.7230 & 0.4700 & 0.4086 & 0.9414 & 0.6806 & 40.0 & \\
\hline 04 & $0.937 !$ & .0783 & 0.0734 & 0.8640 & 0.4200 & 0.3466 & 0.9414 & 0.8134 & 57.4 & 59.1 \\
\hline 204 & 0.9814 & 0.0783 & 0.0768 & 0.9046 & 0.4100 & 0.3332 & 0.9414 & 0.8515 & 60.9 & \\
\hline
\end{tabular}


TABLE A-12

Reactivity Runs For CC/MAP Pretreated IIIinois \#6 Coal

\begin{tabular}{|c|c|c|c|c|c|c|c|c|c|c|}
\hline \multicolumn{7}{|c|}{ ILLINOIS \#6 COAL } & \multicolumn{4}{|l|}{ FRACTION } \\
\hline & & & & & & & INTRINSIC & ADJUSTED & ADJUSTED & \\
\hline & MF COAL & FRACTION & GRAMS ASH & MAF COAL & MF THF & MAF THF & THF INSOLS & MAF COAL & THF COAL & MEAN \\
\hline RUN & IN & ASH IN & IN & IN & INSOL OUT & INSOL OUT & IN FEED & IN & CONV. & CONV. \\
\hline$\#$ & $(g)$ & & $(g)$ & $(g)$ & $(9)$ & $(g)$ & COAL & $(g)$ & $(\%)$ & $(\%)$ \\
\hline$\cdots$ & $\cdots$ & $\cdots \cdot$ & $\cdots \cdots$ & $\cdots \cdots$ & $\cdots$ & $\cdots$ & $\cdots \cdots$ & $\cdots \cdots$ & $\cdots \ldots$ & $\cdots \cdots$ \\
\hline 49 & 0.9424 & 0.1590 & 0.1498 & 0.7926 & 0.5000 & 0.3502 & 0.8828 & 0.6997 & 50.0 & 48.2 \\
\hline 76 & 0.9699 & 0.1590 & 0.1542 & 0.8157 & 0.5400 & 0.3858 & 0.8828 & 0.1201 & 46.4 & \\
\hline 51 & 0.9225 & 0.1590 & 0.1467 & 0.7758 & 0.2500 & 0.1033 & 0.8828 & 0.6849 & 84.9 & 86.5 \\
\hline 191 & 0.9718 & 0.1590 & 0.1545 & $0.8173^{\circ}$ & 0.2400 & 0.0855 & 0.8828 & 0.7215 & 88.2 & \\
\hline 53 & 0.9621 & 0.1590 & 0.1530 & 0.8091 & 0.2300 & 0.0770 & 0.8828 & 0.7143 & 89.2 & 91.0 \\
\hline 194 & 0.9912 & 0.1590 & 0.1576 & 0.8336 & 0.2100 & 0.0524 & 0.8828 & 0.7359 & 92.9 & \\
\hline 55 & 1.0019 & 0.1590 & 0.1593 & 0.8426 & 0.2600 & 0.1007 & 0.8828 & 0.7438 & 86.5 & 88.0 \\
\hline 195 & 0.9718 & 0.1590 & 0.1545 & 0.8173 & 0.2300 & 0.0755 & 0.8828 & 0.7215 & 89.5 & \\
\hline 40 & 0.9423 & 0.1590 & 0.1498 & 0.7925 & 0.8600 & 0.7102 & 0.8828 & 0.6996 & -1.5 & 7.0 \\
\hline 193 & 0.9718 & 0.1590 & 0.1545 & 0.8173 & 0.7700 & 0.6155 & 0.8828 & 0.7215 & 14.7 & \\
\hline 196 & 0.9815 & 0.1590 & 0.1561 & 0.8254 & 0.8300 & 0.6739 & 0.8828 & 0.7287 & 7.5 & \\
\hline 197 & 1.0035 & 0.1590 & 0.1596 & 0.8439 & 0.8500 & 0.6904 & 0.8828 & 0.7450 & 7.3 & \\
\hline 42 & 0.9225 & 0.1590 & 0.1467 & 0.7758 & 0.6100 & 0.4633 & 0.8828 & 0.6849 & 32.4 & 34.6 \\
\hline 192 & 0.9718 & 0.1590 & 0.1545 & 0.8173 & 0.6100 & 0.4555 & 0.8828 & 0.7215 & 36.9 & \\
\hline 44 & 0.9225 & 0.1590 & 0.1467 & 0.7758 & 0.5700 & 0.4233 & 0.8828 & 0.6849 & 38.2 & 38.5 \\
\hline $78^{\star}$ & 0.9699 & 0.1590 & 0.1542 & 0.8157 & 0.6800 & 0.5258 & 0.8828 & 0.7201 & 27.0 & \\
\hline 113 & 0.9455 & 0.1590 & 0.1503 & 0.7952 & 0.5800 & 0.4297 & 0.8828 & 0.7020 & 38.8 & \\
\hline 46 & 0.9424 & 0.1590 & 0.1498 & 0.7926 & 0.4500 & 0.3002 & 0.8828 & 0.6997 & 57.1 & 56.8 \\
\hline 80 & 1.0000 & 0.1590 & 0.1590 & 0.8410 & 0.5000 & 0.3410 & 0.8828 & 0.7424 & 54.1 & \\
\hline 114 & 0.9552 & 0.1590 & 0.1519 & 0.8033 & 0.4400 & 0.2881 & 0.8828 & 0.7092 & 59.4 & \\
\hline
\end{tabular}

* indicates outlying value not used in calculation of mean conversion 
APPENDIX B 
TABLE B-1

\section{Five Factor Analysis of Variance}

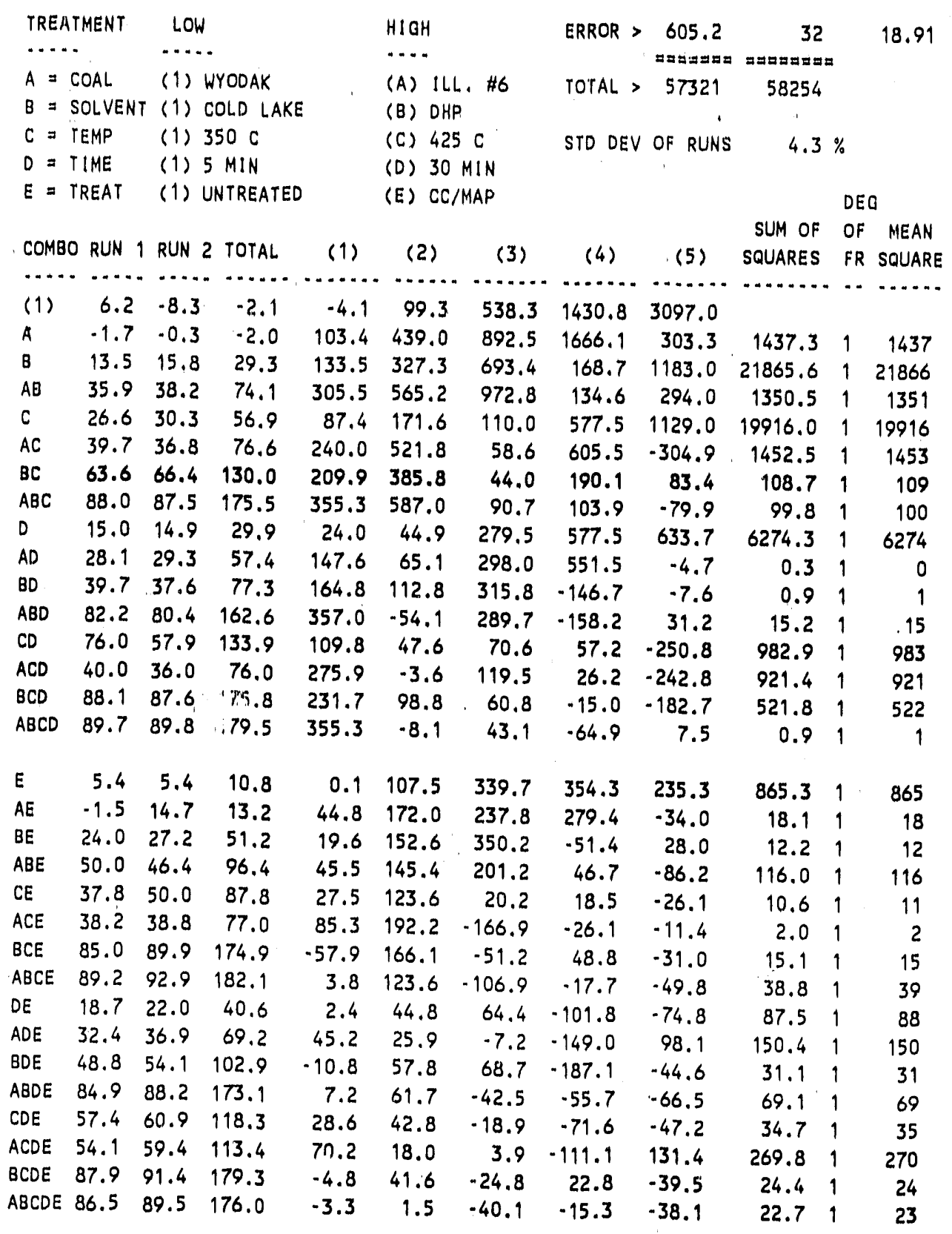



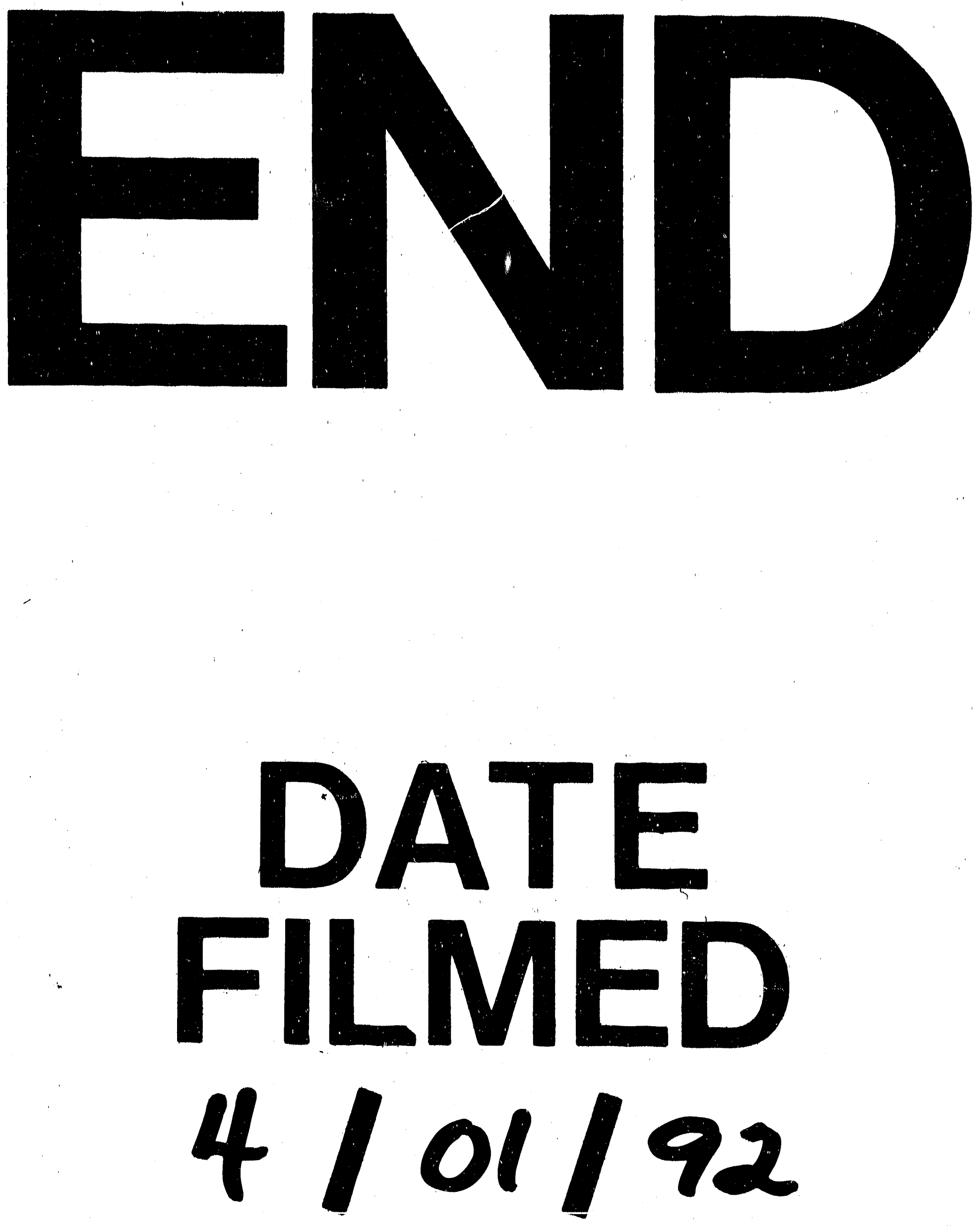
